\title{
Built in dampers for stayed cables in bridges via SMA. The SMARTeR-ESF project: A mesoscopic and macroscopic experimental analysis with numerical simulations
}

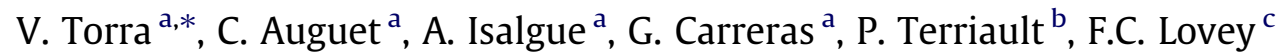 \\ ${ }^{a}$ CIRG-DFA-ETSECCPB, Polytechnical University of Catalonia, E-08034 Barcelona, Catalonia, Spain \\ bépartement de génie mécanique, École de technologie supérieure, Université de Québec, Montréal, Canada H3C 1 K3 \\ ${ }^{\mathrm{c}}$ Centro Atomico Bariloche, Instituto Balseiro and CONICET, 8400 S.C. Bariloche, Argentina
}

\section{A R T I C L E I N F O}

\section{Article history:}

Received 25 July 2011

Revised 26 June 2012

Accepted 5 November 2012

Available online 25 December 2012

\section{Keywords:}

SMA

Passive dampers

NiTi

Stayed cables

Damping

Bridges

FEA

Simulation

Wavelets

Windowed Fourier transform

Frequency analysis

Built SMA damper

\begin{abstract}
A B S T R A C T
Shape Memory Alloys (SMAs) are good candidates for solid-state dampers appropriate for the oscillations of bridge stay cables because of their large recoverable strain, hysteresis and reasonable fatigue-life. This work experimentally analyzes the relevant properties of NiTi SMA and conducts facility measurements, frequency analyzes and simulations of the effects of SMA on stay cables. Appropriate phenomenological SMA models were developed and included in a Finite Element (FE) simulation environment. A complete damping solution for bridge stay cables was developed from these experimental analyzes. This paper detail the required properties for a NiTi SMA and analyzes their performance. For instance, the fatiguelife and several of the thermo-mechanical effects influencing the application of NiTi SMAs are outlined. The damping effect of the SMA was studied in two facilities. The first series of measurements was performed using cable 1 of the ELSA facility (JRC-EU, Ispra, Italy). The second was completed in two campaigns at IFSTTAR (Bouguenais, near Nantes in France). The numeric analyzes and simulated results were completely coherent with these experiments: the SMA dampers also drastically reduce the maximum oscillation amplitude induced by the simulated action. The frequency evolution of the damped cable was studied using direct calculations on the signals, the windowed Fourier transform and Morlet wavelets.
\end{abstract}

Published by Elsevier Ltd.

\section{Introduction}

Improving the quality of life is one of the primary goals for smart materials and systems. The suppression or reduction of cable oscillations induced by external perturbations, such as wind, rain and traffic, is a practical problem for bridges. These oscillations cause progressive damage via fretting, which wears down the steel fibers and reduces the working life-time of the cable and also damages in the anchoring of cables. The European Science Foundation started funding several projects in 2006 via the EUROCORES focus on smart structural systems technologies (S3T) [1]. The project "Shape Memory Alloys to Regulate Transient Responses in civil engineering (SMARTeR)" was focused on problems associated with the cables of the Iroise and St. Nazaire bridges (see for instance,

\footnotetext{
* Corresponding author. Address: CIRG-DFA-ETSECCPB, Polytechnical University of Catalonia, C/Gran Capita s/n, Campus Nord B-4, E-08034 Barcelona, Spain. Tel.: +34 934016859; fax: +34 934016090.

E-mail address: vtorra@fa.upc.edu (V. Torra).
}

Refs. [2-4]). The final results of SMARTeR were published in Ref. [5].

The FP014-SMARTeR (Shape Memory Alloys to Regulate Transient Responses in civil engineering) project was developed in the years 2007-2009 and studied the application of SMA for damping stay cables. The initial studies focused on low-frequency oscillations $(1$ and $3 \mathrm{~Hz}$ ) in the Iroise Bridge located in a free highway $(2+2$ lanes) between Brest and Plougastel (NW of France). The pillars are situated in the platform axis with free lengths of $200+400+200 \mathrm{~m}$. Analysis of the SMA behavior was extended to the higher frequencies involved in the St. Nazaire Bridge $(18 \mathrm{~Hz})$. With a main span of $404 \mathrm{~m}$ and a deck width of $15.00 \mathrm{~m}$, this bridge is situated over the Loire River near Nantes to permit ship traffic and was opened to traffic in October 18, 1975. The first replacement of a damaged cable occurred in 1998. Three cablestays were replaced in the year 2002.

The Echinghen Viaduct (EV), in Fig. 1A-D, is another example of using lengthy cables. The EV is the largest $(1309 \mathrm{~m})$ of the three Boulonnais Viaducts on the SANEF - A-16 toll highway. The light construction elements in the Viaduct $(C)$ are anchored by series 

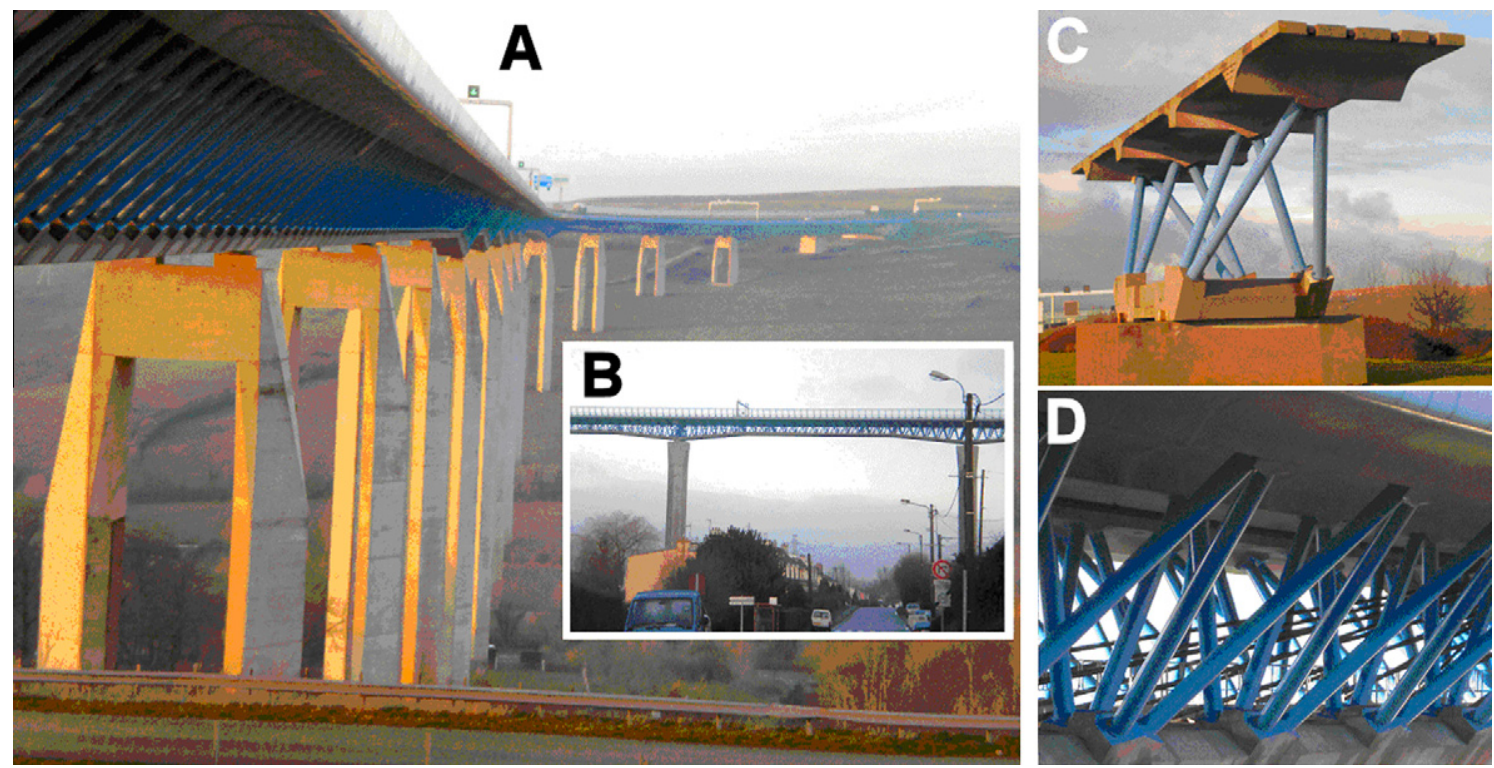

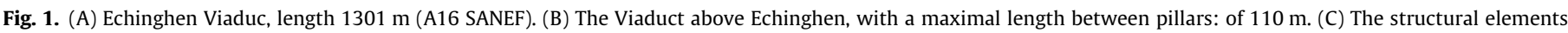
using concrete for the platform and basis linked by cylindrical steel tubes. (D) The cables that links the elements (photographs by V. Torra).

of cables (D). These elements use cylindrical steel tubing to support the concrete pieces (platform and basis). The distance between the piers surpasses $100 \mathrm{~m}$ in the center of the bridge, and the lengthy cables used are sensitive to winds even under $10 \mathrm{~km} / \mathrm{h}$. Video observations obtained in December 2010 show oscillations close to $5 \mathrm{~Hz}$ with amplitudes of nearly $10 \mathrm{~mm}$.

In general, repeated or "continuous" oscillations with different amplitude scales, such as those induced in large structures (skyscrapers and high towers) by wind and rain, are frequently damped via semi-active systems such as tuned mass dampers using magneto-rheologic fluids [6,7]. These systems require electrical power and are activated by constantly running computers (24/24-365/ 365 ) that require some amount of permanent supervision. For large bridges, the use of magneto-rheologic dampers also requires continuous power and permanent supervision. MR dampers are a good solution for wind and rain induced oscillations. The Dongting Lake Bridge (nearly $1 \mathrm{~km}$ long) is a cable-stayed bridge over Dongting Lake [8] in northeastern Hunan Province, China that actually uses MR dampers [9]. In semi-active systems, the problems introduced by the intrinsic long-term instability of the damping fluid and changing hardware control and proprietary software need to be carefully solved for each adaptation of the system. As such, a guaranteed, passive and efficient method seems to be a better approach. In recent literature, Shape Memory Alloys (SMAs) $[10,11]$ was suggested for damping in civil structures [12-20].

This paper focuses on acquiring the basic detailed knowledge of SMA properties required to reduce the oscillation of cables, thus increasing the cable lifetime and developing design rules for sizing the SMA dampers from cable data. The use of SMAs to damp stay cables requires a deep knowledge of the static and dynamic SMA properties [21-25]. The particular working of a SMA is associated to its martensitic transformation, a phase transition with classical sensitivity to temperature changes per the Clausius-Clapeyron thermodynamic equation. Some recent studies using NiTi for damping in civil engineering did not include an in-depth analysis of SMA properties that would ensure guaranteed behavior. The effects of temperature changes (summer-winter) for dampers situated on a roof were not considered in Refs. [26,27]. The primary goal of this work is to produce a passive device, i.e., an unsupervised damping solution, for stay-cable bridges using SMAs. This work shows that the oscillation amplitude of the cable might be reduced by an appropriate SMA damper by a factor of more than 2 , which would increase the useful life of the cable.

This work emphasizes the SMA properties related to the application requirements. Section 2 is devoted to the basic NiTi SMA properties and pays special consideration to the conditions necessary for the application. Section 3 focuses on the results from the experimental facilities. Section 4 is devoted to numerical analysis and Finite Element Analysis (FEA) simulations [28]. Section 5 is devoted to remarks on and improvements in the SMA damper application, i.e., the appropriate design of SMA dampers. The paper ends with the conclusions in Section 6 followed by the acknowledgements and references. The study of why oscillations originate in some cables but not in other remains outside the scope of this paper.

\section{Basic SMA properties}

The properties particular to an SMA relate to its martensitic transformation between metastable phases. This transformation between solid phases is always considered a first order phase transformation (with both dissipated and absorbed latent heat) with hysteresis. The high temperature phase, or austenite (the beta phase), is a body-centered cubic (or bcc) crystalline phase, and the martensite has lower symmetry such as orthorhombic or monoclinic. The primary interest in SMAs for damping is their hysteresis cycle converting mechanical work into heat $\left(Q_{\text {net }}\right)$. The SMA works as a passive system that extracts mechanical work $\oint \vec{f} d \vec{r}$ every cycle of the oscillating system without requiring computational or external power supplies. The hysteretic energy is transformed in heat as shown in the following equation:

$\oint \vec{f} d \vec{r}=Q_{\text {net }}$

The effects of both the room temperature and self-heating were studied in this work along with the changes caused by both yearly and daily temperature evolution and those induced by hysteretic behavior during cycling. Furthermore, the effect of wind-induced forced convection, which modifies the heat transfer, was qualitatively studied. 
While the damping of stay cables is similar to that of earthquakes, the general requirements are different. The number of cable oscillations is much higher than required for earthquakes (under 2000 working cycles). For storms lasting 3 days, the number of oscillations is highly relevant (i.e., $3 * 86,400 *$ frequency). The number of working cycles for the Iroise Bridge ( 1 and $3 \mathrm{~Hz}$ ), large cables of the Echinghen Viaduct $(5 \mathrm{~Hz})$ and St. Nazaire Bridge $(18 \mathrm{~Hz})$ are approximately $0.8,1.5$ and $4.7 \mathrm{M}$ cycles, respectively. Furthermore, the dampers for these cables are expected to remain eventually in contact with sunlight, wind and rain. For cable frequencies below $5 \mathrm{~Hz}$, the working time is approximately 1 year ( 3 or 4 strong storms). Above $15 \mathrm{~Hz}$, the dampers need to be checked after each storm. In earthquake mitigation, several quiet decades were possible between installation and use. The changes in the transformation temperatures from diffusion and the associated temperature aging at, for instance, $100{ }^{\circ} \mathrm{C}$ were quantitatively evaluated [5,19,20,29-31].

The NiTi wires used for the experiments described within this paper were furnished in the pseudo-elastic state by Special Metals, USA. The actual furnisher was Memry Corporation Bethel, CT 06801, USA, a division of SAES Getters, Italy. The samples were finished with a light (gray) oxide surface (diameter $2.46 \mathrm{~mm}$ ). The As temperature was $-30^{\circ} \mathrm{C}$. The nominal composition was $\mathrm{Ni}$ 55.95 wt\% with the rest Ti. Before using in the experimental facilities, the wires were trained for 20 (Institut français des sciences et technologies des transports: IFSTTAR) or 100 cycles (European Laboratory for Structural Assessment: Joint Research Center, European Union, ELSA-JRC-EU) with a maximal strain of $8 \%$. The samples for the pure thermal aging studies were used as received. The selfheating effects were attributed to the release and absorption of latent heat. The net transfer of $Q_{\text {net }}$ to the surroundings via both released $\left(\ell_{\mathrm{p} \rightarrow \mathrm{m}}\right)$ and absorbed $\left(\ell_{\mathrm{m} \rightarrow \mathrm{p}}\right)$ latent heat are processes that operate under the heat transfer and the Fourier's law for both the martensitic transformation of the wires and the required cycling conditions.

The classical heat-transfer rules indicate that the cycling process was influenced by four factors: the external temperature, convection in the sample surface, the working frequency and the intrinsic transformation mechanism. First, the experimental analysis only considered the fatigue-life of NiTi alloy with regards to tension. In our case, the sample always remained under pure tensile stresses. Both compression and bending were avoided in the SMA damper outlined (see Fig. 20 in the part 4). Later, the temperature effects associated with self-heating and the working cycles were considered and evaluated for different working frequencies (under 0.01 and up to $16 \mathrm{~Hz}$ ) and moderate external winds. The pauses between working cycles were studied. The temperature and stress aging were also quantitatively analyzed.

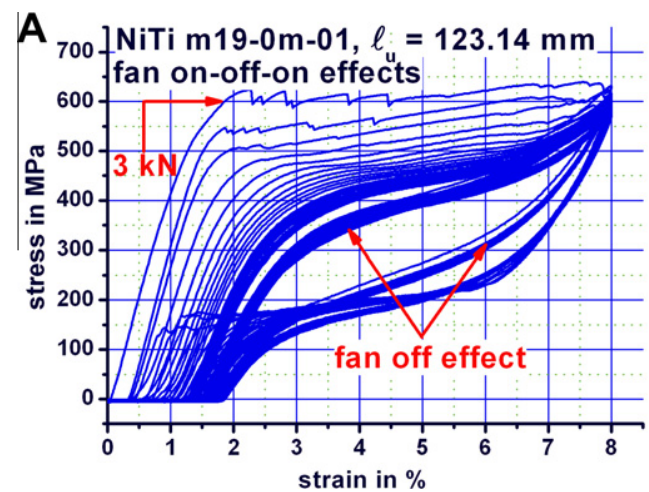

\subsection{Fatigue behavior}

The effects of a large storm with strong winds might remain active for several days (3-5), and the SMA requires at least 0.5 million working cycles to be functional. The first damping condition required for reducing the oscillation amplitude is that the fracture life must overcome the minimum number of working cycles required. In addition, the dampers can be directly subjected to aggressive external conditions (rain, sun and oceanic winds), and $\mathrm{NiTi}$ is the most appropriate material because of its corrosion resistance. We chose to use NiTi for its excellent wet performance. The alloy is mounted in pure traction [32] to avoid compressive or bending parts. For instance, other complex paths [33-35], such as axial torsion and/or bending used in orthodontic bits for drilling were suppressed because they apparently show shorter life.

For a net strain below $1.5 \%$, the number of working cycles overcomes 4 million with reduced hysteretic energy. For samples $100 \mathrm{~mm}$ in length with a $2.46 \mathrm{~mm}$ diameter, the dissipated energy remains near $0.1 \mathrm{~J} /$ cycle. For each expected position in a lengthy cable with displacements near $\pm 40 \mathrm{~mm}$, the damping action reduces the displacements to at least half (i.e., residual peak to peak displacement of near or under $\pm 20 \mathrm{~mm}$ ). The required SMA length for one $40 \mathrm{~mm}$ deformation or $1 \%$ strain was $4 \mathrm{~m}$, at which point the dissipated energy overcomes $4 \mathrm{~J} /$ cycle. Based on this idea, it is possible to install the SMA between the cable and the platform or a straight line of SMA wires between the bridge cables that link two consecutive cables. This SMA distribution also permits some damping of "out of the plane" oscillations.

Fatigue-fracturing is a critical problem that requires adapted analysis for each application. A great number of studies are devoted to orthodontic [36] problems using NiTi. In general, the representation between the strain and number of working cycles reduces the information garnered [37]. For NiTi alloys, thermal cycles of $0.7-0.5 \mathrm{in} \%$ indicate a fracture level between $10 \mathrm{k}$ and $10 \mathrm{M}$ cycles [38]. The stress from the working cycles was found to be between 2000 and 50,000 for NiTiCu in Ref. [39]. CuAlBe was appropriate for damping applications with lower number of cycles, according to Ref. [40] and the references therein.

The study of fatigue-fracturing was primarily accomplished using an MTS 810 with a $100 \mathrm{kN}$ load cell working in span control. The MTS uses a homemade furnace to obtain moderate temperatures, i.e., under $100{ }^{\circ} \mathrm{C}$. The cycling behavior study of NiTi wires includes a 20 (IFSTTAR) or 100 slow cycle training at $0.01 \mathrm{~Hz}$ with a higher strain at $8 \%$ as shown in Fig. 2A. Using a fan increases the sample heat transfer (convection) and modifies the stressstrain behavior as shown in Fig. 2A. Next, the fatigue cycles were measured using an appropriate strain. The measurement analysis includes the hysteretic energy calculated from the MTS files using

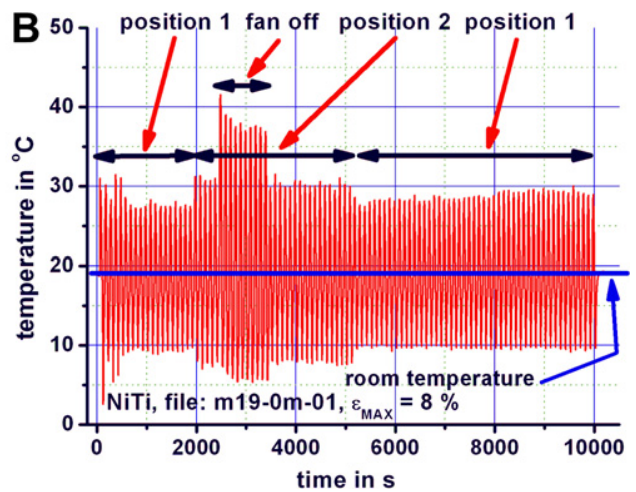

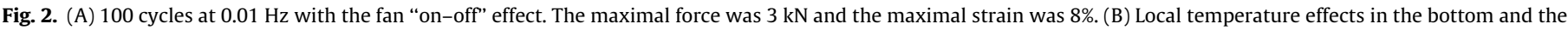
middle of the sample. The fan "on-off" actions induce \pm 10 or $\pm 15^{\circ} \mathrm{C}$. 
formula (1). The temperature measurements permit the evaluation of self-heating. One or two thin OMEGA K thermocouples wrapped around two positions in the SMA wire measured the time evolution of the local temperature.

Fig. 2B shows an overview of the temperature effects associated with both mechanical cycling at $0.01 \mathrm{~Hz}$ and the fan effect. The experimental observations indicate that, with a fan, the temperature oscillates by approximately $\pm 10 \mathrm{~K}$ around room temperature. Fig. 2A shows the effects on the hysteresis of stopping the fan for several working cycles during the training process. This effect is well visualized in the temperature versus time plot shown in Fig. 2B. When the fan is stopped, the maximum temperature span increased to as much as $\pm 15 \mathrm{~K}$ from room temperature. This temperature span remained practically invariant for different positions ( 1 and 2 ) in the sample.

The initial transformation stress in an "as furnished" wire working via sinusoidal cycles at $0.01 \mathrm{~Hz}$, was approximately $3 \mathrm{kN}$ or $630 \mathrm{MPa}$ (Fig. 2). A series of 100 sinusoidal cycles at $0.01 \mathrm{~Hz}$ with an $8 \%$ strain reduced the initial maximal stress and increased the permanent initial strain. The transformation progressively develops an S-shape qualitatively similar to the cycles in a Cu-based polycrystalline SMA [30]. This transformation was subject to minor changes. During training (Fig. 2A), the maximum hysteresis width decreased progressively from 400 to approximately $200 \mathrm{MPa}$. The most relevant changes in hysteresis energy and creep occurred in the first $60-100$ cycles. The hysteresis was reduced to a third, and the creep increased by up to $2 \%$ (Fig. 2A).

The experimental results obtained for the fracture-life of approximately $130 \mathrm{~mm}$ long samples is shown in Fig. 3. This figure shows several tests of the fatigue life obtained for the "pure" traction using both "as furnished" and previously trained NiTi wires (diameter of $2.46 \mathrm{~mm}$ ) at $20^{\circ} \mathrm{C}$. The tests using strains of up to $8 \%$ showed a reduced fatigue-life between 10,000 and 30,000 cycles. Up to 100,000 working cycles were achieved when a lower strain was used (5\%), and the stresses were also important (300 MPa). For the fracture-life to overcome $1 \mathrm{M}$ cycles, the strain used must remain under $1.0 \%$. Reducing the maximum strain from $8 \%$ to $1 \%$ was accomplished by reducing the stress from $600 \mathrm{MPa}$ to $200 \mathrm{MPa}$. Two types of the sample crash were observed. For some samples, the crash occurred between the grips. For the majority of samples, the crash occurred at the grips. The measurements showed similar lifetime behavior for the two macroscopic fracture types even when the upper and lower parts of the sample (situated inside the grips) remains under constant, complex stresses that avoids the sample slip.

Because the fracture-life increases as the stress decreases $[41,42]$, several samples were studied under reduced stress, strain

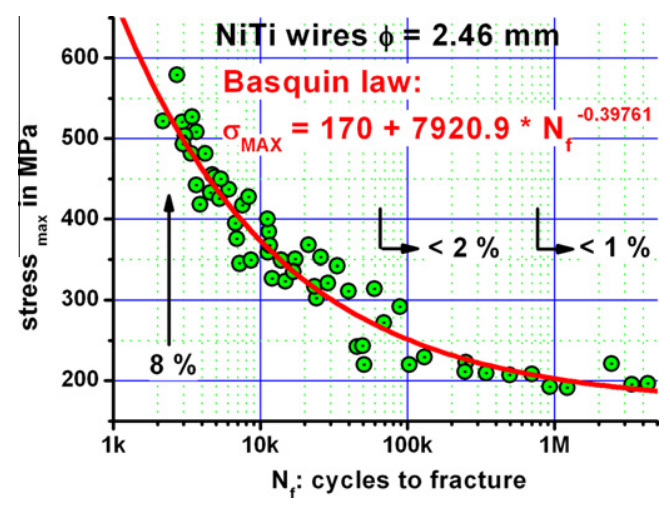

Fig. 3. Fracture against the number of working cycles and the Basquin law for trained samples. The arrows show the associated strain: an increased life with progressively reduced strain. and hysteretic energy. Reducing the net strain by up to $1 \%$ reduced the net force in the sample by $1 \mathrm{kN}$ with a stress of nearly $200 \mathrm{MPa}$. At this level, sample fracturing occurs at a level of practical interest: i.e., for 3-5 million working cycles. The hysteretic energy for this reduced strain and studied sample lengths (100-120 mm long with a $2.46 \mathrm{~mm}$ diameter) was approximately $0.1 \mathrm{~J} /$ cycle. Other measurements were made using $550 \mathrm{~mm}$ samples. The measurements made at IFSTTAR used the same samples for the two campaigns (near $1260 \mathrm{~mm}$ ) without crashing. Additionally, the sample used at ELSA where over $4140 \mathrm{~mm}$ long and did not crash during any of the several days realizing tests.

For stay-cable dampers, the SMA length is expected to be over $1 \mathrm{~m}$, and the absorbed energy approaches an appropriate value (some $\mathrm{J} /$ cycle) for damping. The fatigue-life is usually described from experimental data in terms of Basquin's law. The maximum stress $\left(\sigma_{\mathrm{MAX}}\right)$ can be considered linear with a parameter, $x$, which is defined using a negative power (parameter $a$ ) of the number of fracture-life cycles $\left(N_{f}\right)$. The equation reads as follows:

$\sigma_{\text {MAX }}=170+7920.9 *\left(N_{f}\right)^{-0.398}$

The coefficients from an approximate fit are used in Eq. (2), and their coherence with experimental data is shown in Fig. 3. The main difference from a classical material is the increased value of the " $a$ " exponent $(a \approx 0.40)$. The parameter " $a$ " for a standard material remains between $1 / 8$ and $1 / 16$. In our case, the fatigue-fracture process was controlled by the martensitic phase transition and not by the dislocation glides as in classical materials.

Basquin's law satisfactorily fits the full range of experimental data. The measurements were gathered using several strains and sample preparations as well as using samples "as furnished" and aged at $100{ }^{\circ} \mathrm{C}(373 \mathrm{~K})$, with strains from $8 \%$ to less than $1 \%$. Fig. 3 includes data about the associated strains: an $8 \%$ strain provided an $N_{f}$ of less than 10,000 working cycles, less than $2 \%$ strain provided over 50,000 working cycles and less than $1 \%$ strain had a fracture-life of over $1 \mathrm{M}$ cycles with a stress close to or under $200 \mathrm{MPa}$. These measurements were extremely time consuming. When cycling $4 \mathrm{M}$ times at $4 \mathrm{~Hz}$, the measurement fully occupies the equipment for nearly 10 days. The experimental measurements available in the literature cover a lesser number of working cycles in these conditions [33-35].

For the initial cycles using thinner wires, the upper and lower branches of the hysteresis cycle (in $\sigma, \varepsilon$ ) were at a constant stress. The transformation was "localized" and formed martensite "bands". The hysteresis behavior of samples $2.46 \mathrm{~mm}$ in diameter after initial training was progressively modified. The flat branch evolves to an inflexion point (as an S-shaped). In fact, for lower strains (near or under 1\%), the sample temperature analysis shows that the transformation was "distributed" across the entire sample (part 2.3).

Using SMA in dampers requires a constant length for the SMA wires while working. In general, the creep increases progressively during both the initial cycles and when the cycling frequency or oscillation amplitude increases that increase increasing temperature and stress caused by self-heating. Fig. 4A shows the progressive increase of the damper length during the first set of working cycles (i.e., the training of the sample $\mathrm{m} 5$ ). The length increase during cycling needs to be suppressed in the damper behavior or the damper will not smoothes the reduced amplitudes. Fig. 4B with all the creep analysis shows the upper limit of the creep (2.5\%). First, 100 sinusoidal cycles at $0.01 \mathrm{~Hz}$ starting with a strain of $8 \%$ and ending with net strain at $6.1 \%$, which is called training " $a$ ", that induces an SMA creep of nearly 1.9\% (Fig. 4A). Subsequent tests with 21 sets of mixed strains (from $6.1 \%$ to $1 \%$ ) and different cycling frequencies (from 0.02 up to $18 \mathrm{~Hz}$ ) produce a constant mean creep value of approximately $2.5 \%$ (Fig. 4B). The frequency 
for set " $b$ " with 500 cycles was $3 \mathrm{~Hz}$ with a strain of $1.5 \%$. The last set, " $c$ ", had 11,620 cycles at $3 \mathrm{~Hz}$ with a strain of $1.26 \%$. During this last step, the creep remains constant. A minor decrease in the SMA creep was observed at the beginning of each set of cycles, for example, the encircled zone in Fig. 4B. For instance, a minor effect in comparison with the $\beta$-recovery that appears in Cu-based alloys.

\subsection{Stops situated between series of working cycles}

Fig. 5 shows the effects of a short pause between sets of thousands of working cycles at low strain. The increased dissipated energy is primarily associated with minor creep recovery. During these pauses, minor creep recovery induces an increase in the hysteresis cycle and an increase in the energy (which can eventually overcome $100 \%$ ) with an immediate decay in the mean value. For series of slow cycles, i.e., $0.01 \mathrm{~Hz}$, temperature effects should also be considered, and the temperature pattern modifies the transformation cycles. At the end of the cycle the sample temperature is clearly under the room temperature as shows Fig. 2B. During a pause, the temperature returns to room temperature, and the required transformation stress increases. The cycle width increases comparatively. This effect disappears after 3 or 4 cycles, at which point the samples recover their dynamic "steady state" of the temperature distribution.

Local changes are, apparently, relevant; however, simulating several thousand working cycles is sufficient to determine that the "mean" dissipated energy was unaffected by the stops. The global number of working cycles approached 600,000 for minor strains (0.76\%) (Fig. 5A) and $4.5 \mathrm{M}$ cycles as shown in Fig. 5B (strain $1.2 \%$ ). The global energy overcomes $400 \mathrm{~kJ}$ with a similar "stop effect" during pauses. The differences for each set of measurements were attributed to both the MTS artifacts used in the strain limits, experimental artifacts and the room-temperature effects. The measurements were accomplished at discontinuous intervals from March to May 2009 with mounting and dismounting of the samples in the equipment. The energies calculated for a realistic damper were more relevant than for samples with lengths of approximately $120 \mathrm{~mm}$. For a realistic wire with an expected length of more than $2 \mathrm{~m}$ (i.e., over $4 \mathrm{~m}$ for the ELSA measurements) the expected energy/cycle was higher than 1-2 J/cycle.

\subsection{Temperature effects}

The temperature effect can be observed using infrared detectors; however, a preliminary approach can be established using $\mathrm{K}$ thermocouples (chromel-alumel) built from thin wires (diameter: $0.08 \mathrm{~mm}$ ) wrapped around the sample. The electromotive force (e.m.f.) was digitized at $6.5 \mathrm{~Hz}$ using a low cost DMM AGILENT U-1251A linked to a computer via USB with proprietary software. The temperature detected versus time is similar to the strain-time action established by the MTS. When cycling at $0.01 \mathrm{~Hz}$, the temperature tracks the strain and produces a temperature wave centered at approximately room temperature with amplitudes of approximately $\pm 10^{\circ} \mathrm{C}$ or $\pm 15^{\circ} \mathrm{C}$ as per the fan effects. Both spontaneous convection and that caused by a fan modifies the hysteretic energy (see Fig. 2). Both external and self-heating temperature effects modify the position and shape of the hysteresis cycle (Fig. 2A). In training at low cycling frequency $(0.01 \mathrm{~Hz})$ the dissipation and absorption of latent heat produce the temperature oscillation clearly shown in Fig. 2B. The oscillation amplitude is practically independent of the position of the K-thermocouple but was reduced with a fan $\left( \pm 10^{\circ} \mathrm{C}\right)$ compared to without a fan $\left( \pm 15^{\circ} \mathrm{C}\right)$.

At moderate or higher cycling frequencies, the net heat dissipated by hysteresis $\left(Q_{\text {net }}\right)$ increased the mean temperature of the specimen. Consequently, a stress increase is expected based on the Clausius-Clapeyron (CC) thermodynamic equation [43-45]. The $C C$ equation determines the position of the transformation retransformation lines in the coexistent zone (coex) of the two material phases as the temperature, $T$, varies. These thermodynamic rules only consider reversible processes and not the hysteresis cycle (i.e., the transformation and retransformation describe the same thermodynamic pathway). The CC equation determines the slope $\left(\alpha_{\mathrm{CC}}\right)_{\sigma-\varepsilon}=(\mathrm{d} \sigma / \mathrm{d} T)_{\text {coex }}$ at which the stress changes with temperature, at the stress-strain $(\sigma-\varepsilon)$ coordinates for phase equilibrium. At these coordinates, the CC equation reads as follows [45]:

$\left(\alpha_{\mathrm{CC}}\right)_{\sigma-\varepsilon}=(\mathrm{d} \sigma / \mathrm{d} T)_{\mathrm{coex}}=\Delta S_{\mathrm{m} \rightarrow \mathrm{p}} /\left(\varepsilon V_{\mathrm{p}}\right)$

where $\Delta S_{\mathrm{m} \rightarrow \mathrm{p}}$ is the entropy change between the martensite and parent phases, and $\varepsilon$ is the net strain between the phases. A series of experimental measurements using "as furnished samples" and after training ones were used to determine the Clausius-Clapeyron coefficient. The plateau stress value or inflexion point in the stressstrain representation was extracted to establish the $\alpha_{\mathrm{CC}}$ as a constant with a value of 6.64 MPa/K for the NiTi alloys used [45] (see, Fig. 6). The $\alpha_{\mathrm{CC}}$ value changed with the thermal treatment and sample composition. The Clausius-Clapeyron coefficient was required to ensure the appropriate operation of the damper in both summer and winter. These coefficients establish the critical transformation stress tracking the room temperature induced by daily or summer-winter effects.

The cycling frequency modifies the hysteretic behavior by coupling between the transformation, the heat loss and the self-heating (see Fig. 7). The representation of the hysteretic energy against
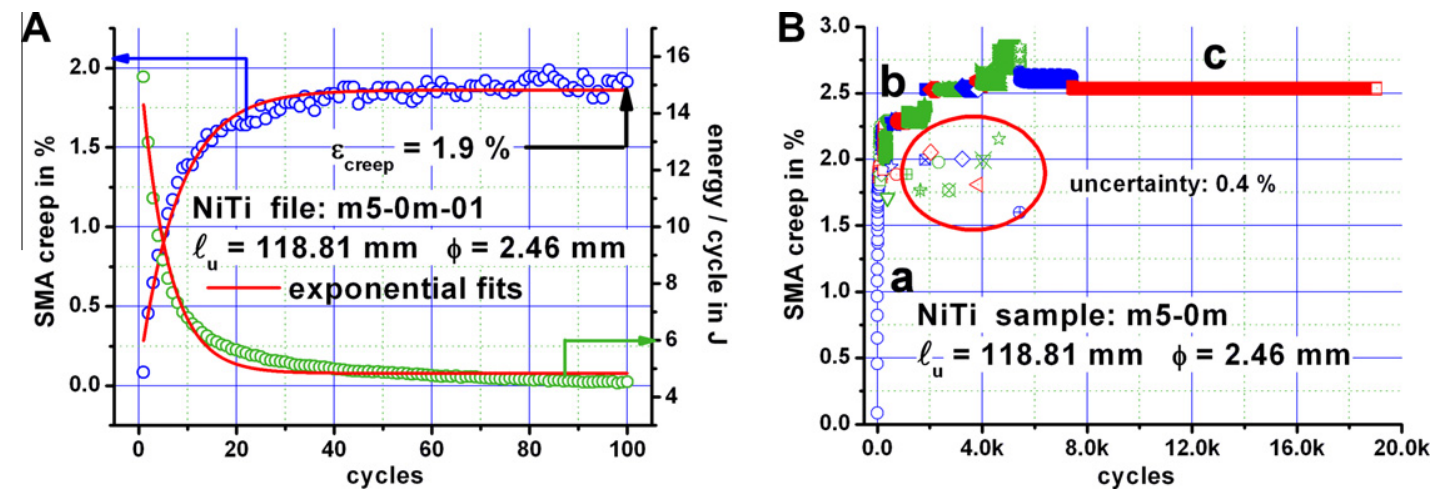

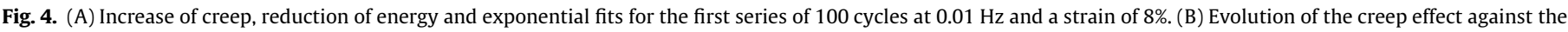
number of working cycles. Encircled: reduced values of the creep after a cycling pause. 

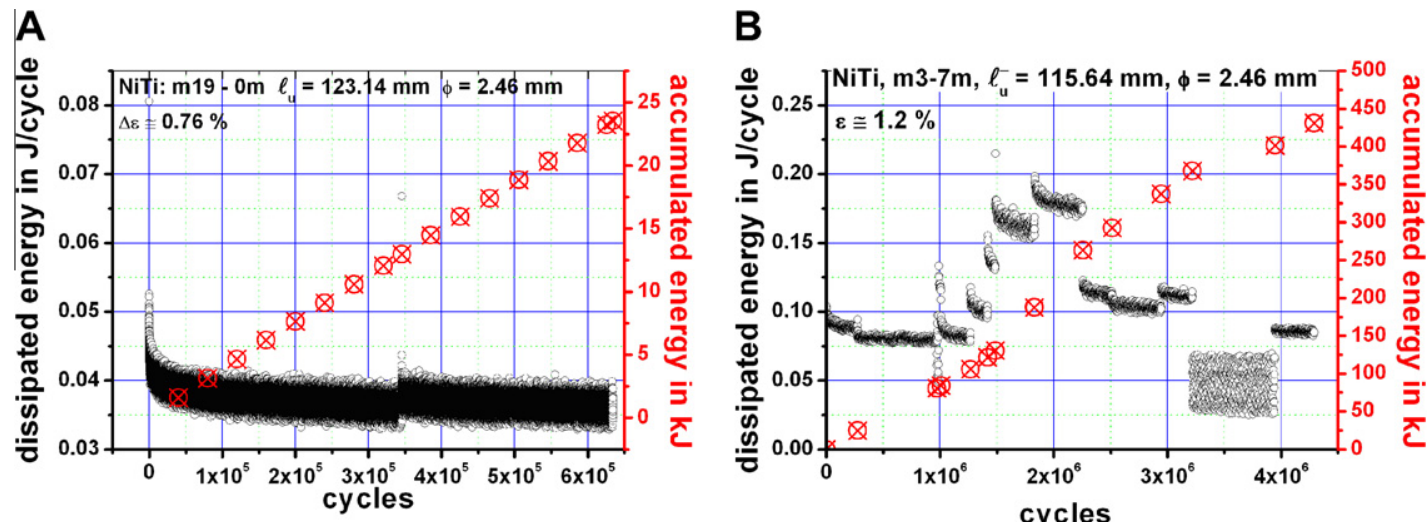

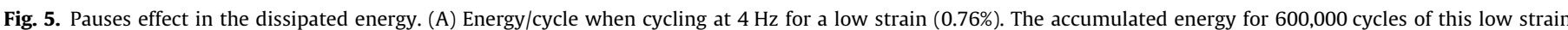
overcomes $23 \mathrm{~kJ}$. (B) Series of 4.5 million of working cycles for 1 ow strain, $1.2 \%$, accumulated energy.

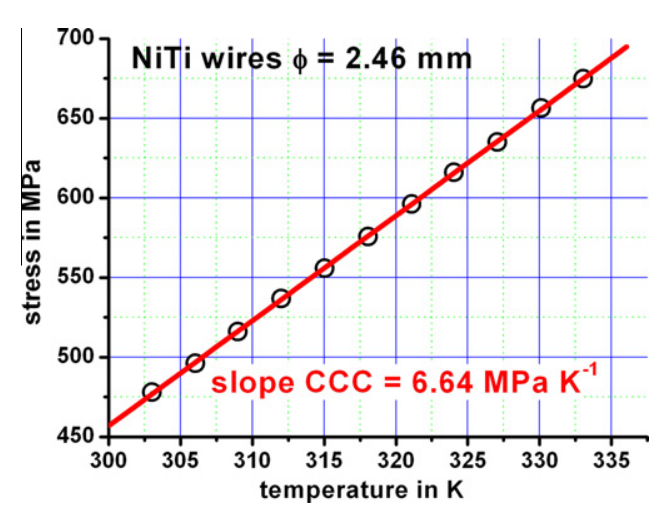

Fig. 6. Experimental data and fit for an evaluation of the Clausius-Clapeyron coefficient (CCC).

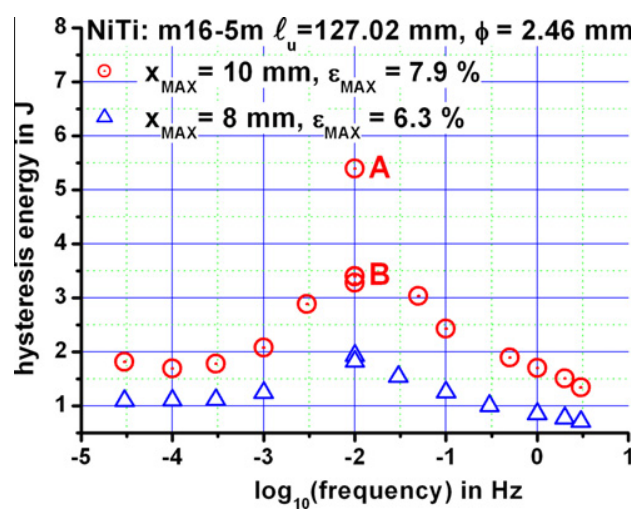

Fig. 7. Hysteretic energy against the cycling frequency. Dots: first series of cycles with a maximal deformation near $8 \%$. Triangles: previously cycled samples by 854,000 cycles, maximal net deformation $6.3 \%$.

the frequency is bell shaped. This effect is more relevant during the initial training (empty dots). Both points A and B were measured using a different number of previous cycles. After a relevant number of working cycles $(845,000$ cycles) the shape was flatted (up triangles). Fig. 8 shows some of the effects associated with the fatigue/fracture analysis. The external temperature oscillations induced by conditioned-air produce a temperature wave (top in Fig. 8). The temperature oscillations induce a wave in the opposite phase of the hysteretic energy (center) and one synchronic with the applied transformation force (bottom).

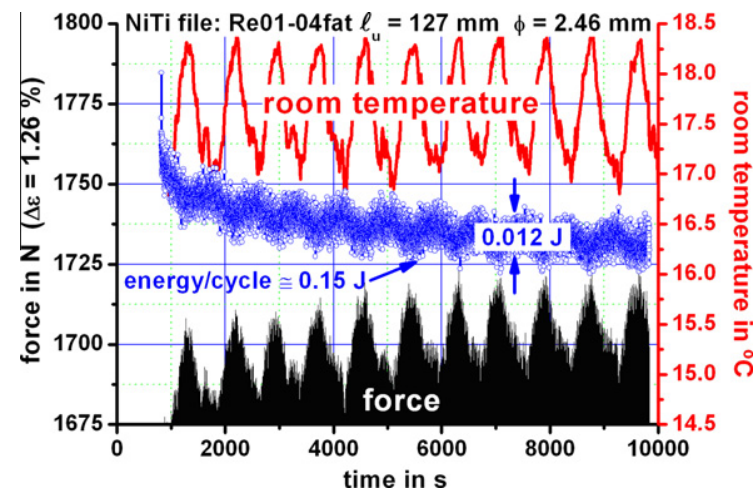

Fig. 8. Top: room temperature effects induced by start/stop in air conditioning Middle: hysteretic energy for a strain of $1.25 \%$ the oscillations track the temperature effects. Bottom: force oscillations.

After training, the dampers are expected to be situated in the free air, usually in the bridge cables, with cycling frequencies of over $1 \mathrm{~Hz}$. In particular, highly cycled samples show reduced fan effects. Increasing the cycling frequency progressively reduces the effects of latent heat via self-compensation and only remains the net hysteretic warming behavior. In our wire, the temperature wave oscillates around the room temperature at $0.01 \mathrm{~Hz}$. The dissipated power, induced by the hysteretic energy, increases progressively at frequencies over $0.1 \mathrm{~Hz}$ (Fig. 9). For a maximum strain of $8 \%$ and $3 \mathrm{~Hz}$, the excess temperature overcomes $25^{\circ} \mathrm{C}$. At lower strain $(0.8 \%)$ and $16 \mathrm{~Hz}$, the excess temperature remains under $5{ }^{\circ} \mathrm{C}$. Faster cycling results in instrumental "artifacts" associated with decreased displacement at the "higher" working frequency observed by the MTS used. The equipment was intended for use at high frequencies but only for the restricted displacements of classical materials, i.e., around one-hundredth of that required for the SMA. The reduction of the displacement distance in the gathered measurements by the MTS artifacts was close to $20 \%$ at $20 \mathrm{~Hz}$. The MTS artifacts appear in Fig. 9B at 2 and $3 \mathrm{~Hz}$. In C (at $16 \mathrm{~Hz}$ ), the same nominal strain was reduced to approximately $20 \%$ relative to the value at $8 \mathrm{~Hz}$.

The experimental measurements of the sample temperature in trained materials establish that reduced transformation was effectively realized in the complete sample. Using reduced strain (1.62\%) at $2 \mathrm{~Hz}$ shows similar temperature oscillation (i.e., $2 \mathrm{~K}$ ) for all the sample positions (Fig. 10).

\subsubsection{Temperature and stress aging effects}

The effects of temperature aging at $100^{\circ} \mathrm{C}$ without or with stress inducing partially transformed samples were studied. The 

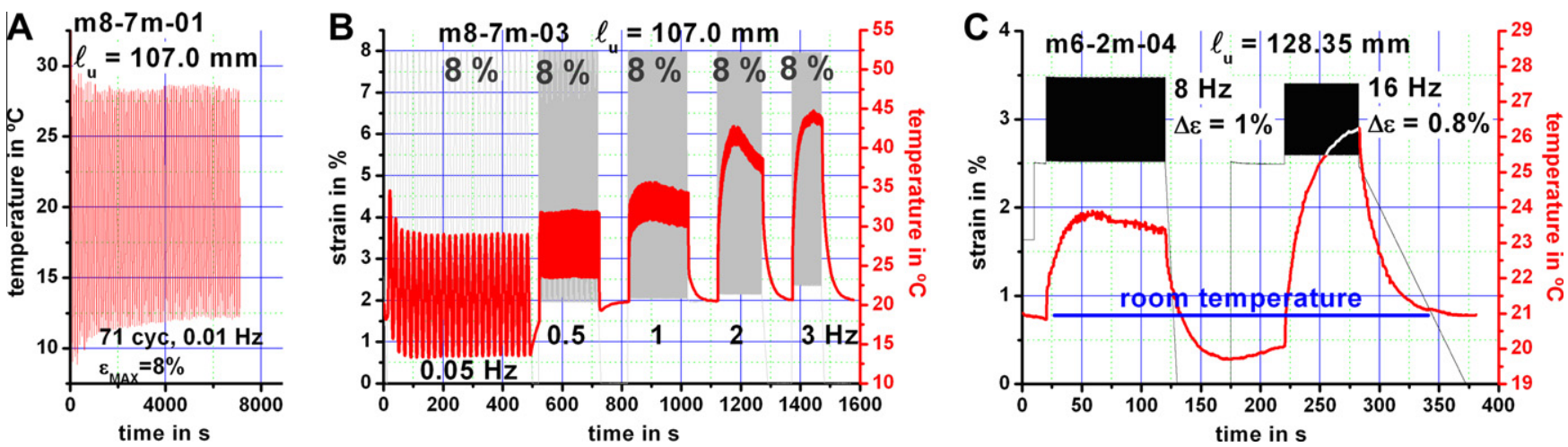

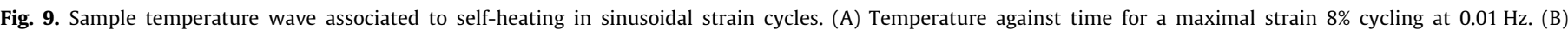
Temperature evolution for a maximal strain $8 \%$ from 0.05 to $3 \mathrm{~Hz}$. (C) Temperature associated to faster cycles at 8 and $16 \mathrm{~Hz}$.

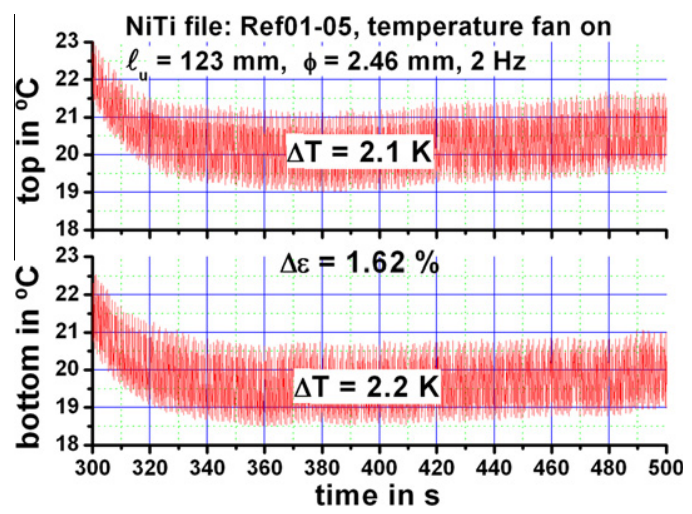

Fig. 10. Temperature effects on cycling. Simultaneous temperature measurement in top and bottom of the sample using reduced strain cycling (from $\varepsilon=0 \%$ to $\varepsilon=1.62 \%)$ at $2 \mathrm{~Hz}$.

primary effect of temperature aging was an increase in the transformation temperature from the parent to the R-phase of nearly $20^{\circ} \mathrm{C} /$ year. One year of stress (strain: $7 \%$ ) and temperature aging increased the maximum stress from $3000 \mathrm{~N}$ to $4000 \mathrm{~N}(600-$ $800 \mathrm{MPa}$ ). In other words, the S-shaped hysteresis cycle had an increased slope of up to $30 \%$. The expected effect at practical temperatures (up to $50^{\circ} \mathrm{C}$ ) and using reduced pre-stresses (up to 50-100 MPa) was significantly less.

\subsubsection{Summer-winter actions}

The external effects of summer-winter temperature changes can induce relevant changes in the SMA. The study was conducted between $40^{\circ} \mathrm{C}$ and $-20^{\circ} \mathrm{C}$, which is similar to the changes in Catalonia at the northwestern Mediterranean basin. This study focused on trained samples with S-shaped hysteresis cycles. According to the Clausius-Clapeyron equation, the changes in the temperature between winter and summer modify the position of the hysteresis cycle in the stress-strain-temperature diagram. When flat cycles (i.e., thinner wires) were used at lower temperatures (under $A_{f}$ ), the SMA remained in the martensite state after stress induced transformations without any retransformation or damping action. The training for $2.46 \mathrm{~mm}$ wires avoid two parasitic effects: (1) the creep remained constant and the sample length increase with cycling was zero, and (2) the flat cycle in thinner wires was converted to an S-shaped cycle. A detailed analogue analysis was clearly necessary for materials with flat cycles before their adequacy for the desired application could be established.

The damping behavior under external temperatures was studied using an external cooling-heating chamber in the INSTRON equipment. The plot of working temperature versus time and the associated hysteretic energy are shown in Fig. 11A and B. A previously cycled sample was used in these examples with a maximum strain of 5\% to avoid any unexpected crash in the study. Eventually, the maximal available strain for the sample approached $5.5 \%$. In general, the SMA creep not overcomes $2.5 \%$ as been established in Fig. 4B. The dissipated energy worked reasonably well for several temperatures between 40 and $-20^{\circ} \mathrm{C}$ (see Fig. 11).

This analysis used continuous cycles at $0.05 \mathrm{~Hz}$ with a maximal strain of $5 \%$. At low temperatures, the low strain portion of the SMA remains in the martensite phase, which reduces the expected strain (i.e., cycles at B and A). Appropriate reheating (cycles at E) recovers the previous hysteretic behavior by converting the martensite to austenite. As a consequence, at the extreme winter temperatures studied (i.e., at $-20^{\circ} \mathrm{C}$ ), the damper cannot smooth the reduced amplitudes: i.e., from $0 \%$ to $2.5 \%$ in cycle $\mathrm{A}$ (Fig. 11B). Increasing the oscillation amplitudes (between $2.5 \%$ and $5 \%$ ) initiates the dissipation. A cooled damper is appropriate to partial smoothing of "larger amplitudes." As a working hypothesis, the self-heating progressively increases the damper temperature with a progressive increasing of the damping effect. Thus, the damper progressively actuates in better conditions. Fig. 11B suggests that the damper can work at even lower temperatures with each additional $10 \mathrm{~K}$ of cooling reducing the practical strain by $1 \%$, i.e., the damper can work at external temperatures as low as $-30{ }^{\circ} \mathrm{C}$.

\section{Tests at facilities}

Realistic tests of the SMA damping of stay cables were realized using two different facilities. First, several measurements were carried out using cable number 1 of the ELSA laboratory facility (Fig. 12). This cable is $45 \mathrm{~m}$ long and built with four sets of wires ( $15 \mathrm{~mm}$ in diameter) inside a protective tube that is $75 \mathrm{~mm}$ in diameter and filled with wax. The ELSA cable is inclined at $21^{\circ}$ and is under $250 \mathrm{kN}$ of tractive force. Only one NiTi SMA wire was used (2.46 $\mathrm{mm}$ in diameter and $4140 \mathrm{~mm}$ long after training). When the maximum peak to peak amplitude of oscillations was $120 \mathrm{~mm}$, the strain in the SMA wire did not surpass 3\%. In general, the damper effect supposes an amplitude reduction of one half. When the maximum amplitudes were reduced to one half or less $( \pm 30 \mathrm{~mm})$ the damped strain remained under $1.5 \%$. The hypothetical strain for file s071 without any SMA was $2.7 \%$. When working, the strain in the SMA is relatively low; file s079 of Fig. 13 had a maximum strain of approximately $1.3 \%$. This is a reasonable value associated to the larger fracture life of the SMA. The vertical force exciting the oscillations was applied to the cable at $27 \%$ of its 

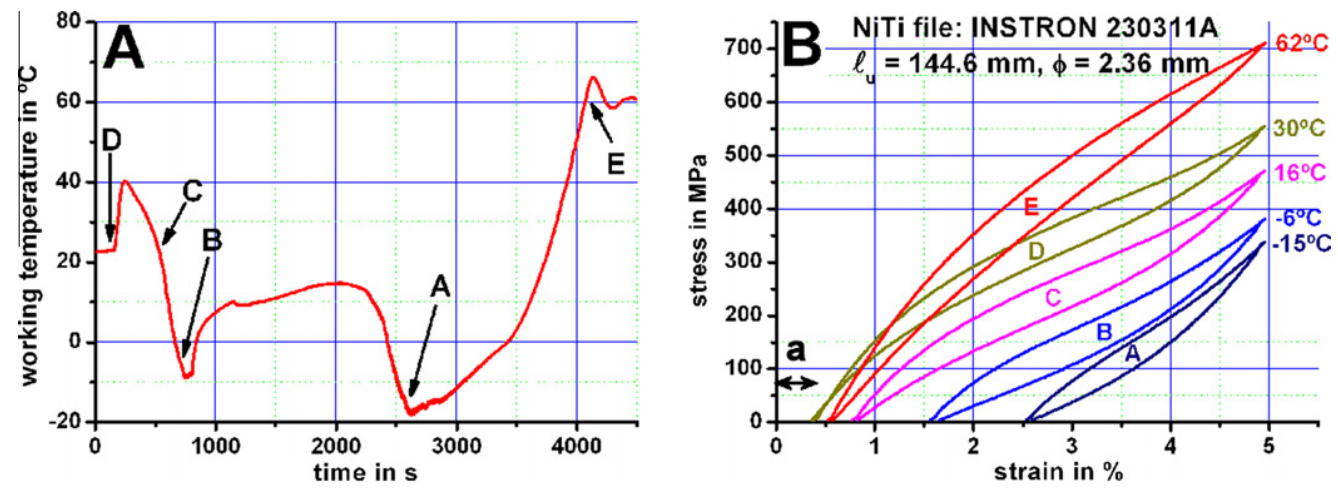

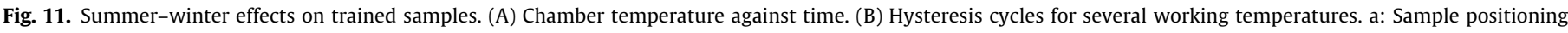
effect by grips adaptation.
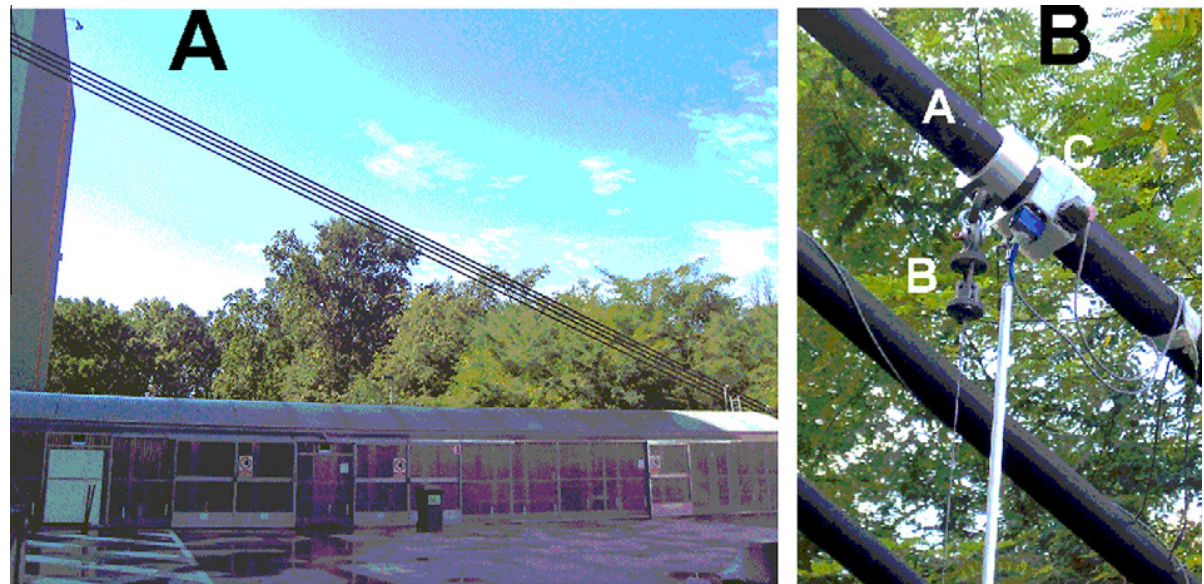

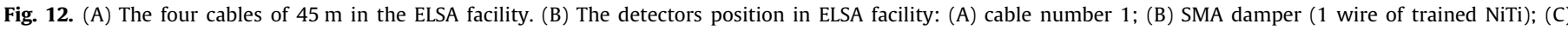
accelerometers for further studies (photographs by V. Torra).

length. The SMA damper was also installed vertically at $22 \%$ of the cable's length.

A second series of measurements was performed at the IFSTTAR facility (Fig. 14) the using available horizontal cable with a length of $50.5 \mathrm{~m}(\ell)$ and $57 \mathrm{~mm}$ diameter with traction stress of approximately $1 \mathrm{MN}$. The mass per unit length was $16.1 \mathrm{~kg} / \mathrm{m}$, and the cable was made of steel ( $E=200 \mathrm{GPa})$. The cross-section of the cable was composed of 159 wires strands forming the core with seven additional layers. The outer diameter, cross-section area and moment of inertia are $55.6 \mathrm{~mm}, 1936 \mathrm{~mm}^{2}$ and $3.03 \times 10^{-7} \mathrm{~m}^{4}$, respectively. Their shape was similar to the standard unwaxed cables used in many bridges. Experimental study both with and without damping demonstrates a spectacular reduction of the oscillation's amplitude for each case. A partial analysis at the end of this section focuses on the frequency analysis using the fast Fourier transform (FFT), the windowed Fourier transform (WFT) and the Morlet wavelet transform (MWT) in the oscillations damped by the SMA. A rough approach permits the interpretation of the frequency change in terms of the force against the strain applied by the SMA.

\subsection{The ELSA results (Joint Research Center-European Union, Ispra, Italy)}

The analysis was devoted to determining the oscillations induced by periodic external forces (forces of 49, 98 and $196 \mathrm{~N}$ ) acting at the resonance frequency, $1.8 \mathrm{~Hz}$ (free) and $2.05 \mathrm{~Hz}$ with
SMA (Fig. 13). A reduced pre-stress between 0 and 100 MPa was always used. The maximum cable oscillations, $\pm 80 \mathrm{~mm}$ for instance, were equivalent to strains under $3.9 \%$ in the SMA wire system. When the oscillations produce a strain below $0.5 \%$, the SMA system remains in the parent phase without energy dissipation by the SMA. For these lower strains, the actions of the wax remain to reduce the oscillation amplitude. Fig. $13 \mathrm{~A}$ includes a direct evaluation of the damped frequency from the time between each oscillation. The frequency change produced by the SMA damping was close to $0.3 \mathrm{~Hz}$. This frequency is lower at the maximum amplitude $(2.03 \mathrm{~Hz})$ and increases when the oscillation amplitude decreases. See the empty dots in Fig. 13A. In fact, reducing the oscillation amplitude increases the mean stiffness of the SMA in agreement with the frequency increase as shown in the frequency analysis in part 3.3.

Fig. 13B outlines the more rapid decay (nearly two times faster) when the cable is under twin damping action (SMA and wax) relative to the spontaneous decay induced by just the wax. The action of the SMA reduces the maximum amplitude from file s079 to $1 / 3$ that from file s071.

3.2. The IFSTTAR results (The French institute of science and technology for transport, development and networks in Bougenais, Nantes, France)

This part is devoted to the experimental results performed for the cable installed in IFSTTAR (Fig. 14). The IFSTTAR cable oscillates 

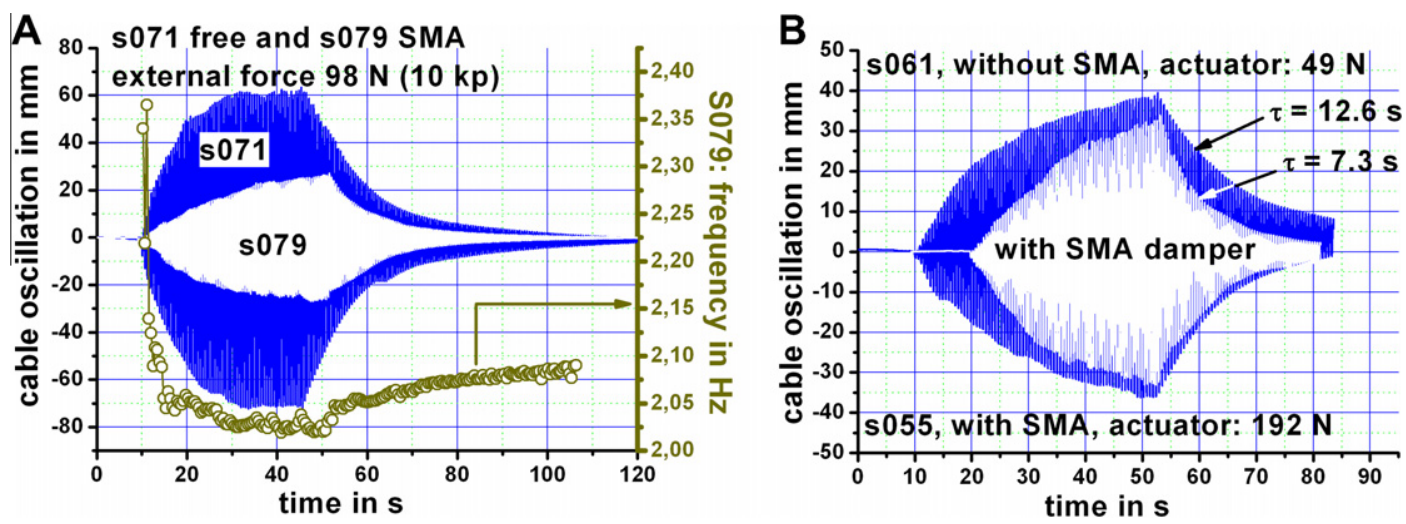

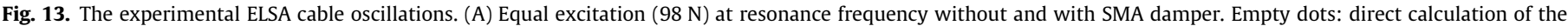
frequency against time for the measurement s079. (B) Similar oscillations for loads of 49 and 192 N. The time constants values show increased slope with SMA.
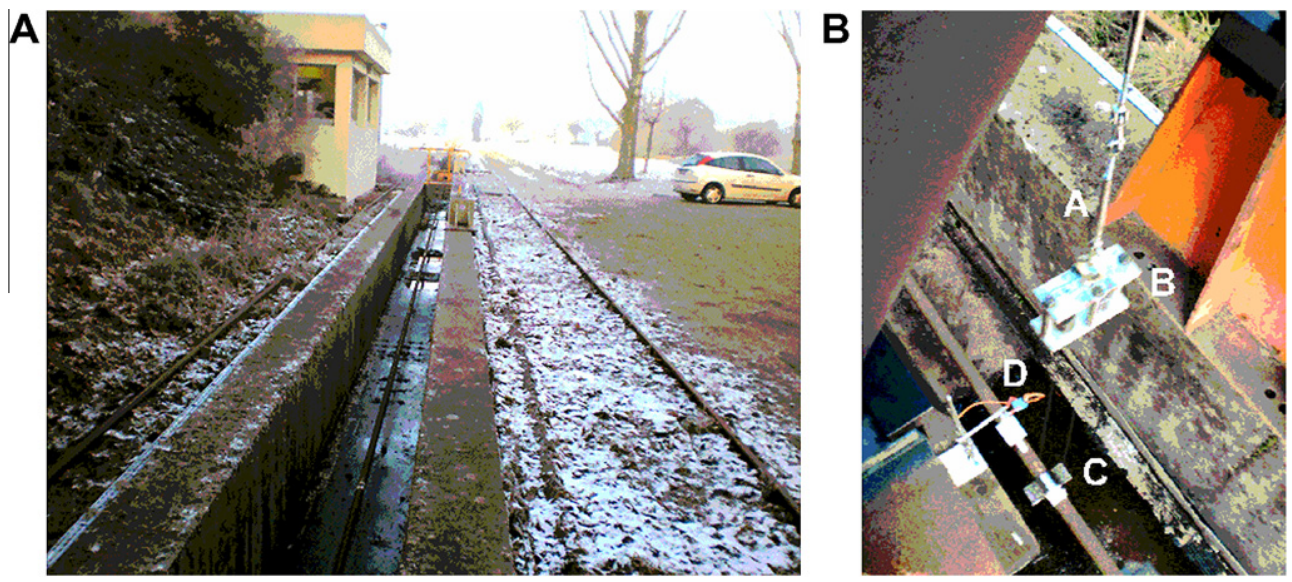

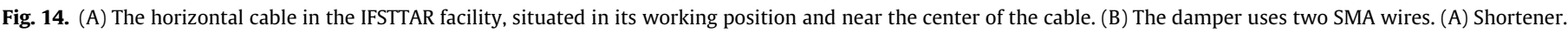
(B) Upper fixation device. (C) Lower fixation of SMA wires. (D) Laser sensor (photographs by V. Torra).

without any explicit self-damper. The experimental equipment in IFSTTAR, Nantes, France, and the cable position only permits transitory studies involving the vertical displacement (up) of the cable by a measured force and sudden stress release (Fig. 14B). The action involved the decay of one Heaviside step inducing oscillations in the cable (Fig. 15A and B).

The experimental observations were made by inducing oscillations in the middle of the cable $(\ell / 2)$ both without (free cable) and with a SMA damper built by two $1260 \mathrm{~mm}$ long NiTi wires. The SMA was somewhat shorter than expected for a realistic application because of the available length imposed by the equipment. Other tests were conducted situating the actuator and/or damper at cable positions corresponding to $\ell / 4, \ell / 6, \ell / 8$ and $\ell / 16$. The vertical position of the cable (the oscillation amplitude) was detected using one or two lasers, and the results were stored using a sampling frequency of $300 \mathrm{~Hz}$. Fig. 15A shows the time evolution of the oscillation amplitude without any SMA after the return of the Heaviside signal of $4 \mathrm{kN}$. The spontaneous damping of the cable was very small, approximately $20 \%$ in $1 \mathrm{~min}$. As the spontaneous damping in the cable was greatly reduced, all attempts to arrive at a steady state of the cable oscillation via "handmade" actions (as in ELSA) were unsuccessful. Fig. 15B shows the effect of the SMA damper on the oscillation amplitude using the same excitation (one Heaviside step of $4 \mathrm{kN}$ ). The effect of the SMA at this privileged position was quite interesting. A reduction of the oscillation amplitude to "zero" was obtained in approximately "ten" seconds. According to the measurements in Fig. 15, the maximum strain for the SMA damper was close to $7.3 \%$ (free) and $4.8 \%$ (damped), which is extremely larger for SMA wires with appropriate lifetimes, and then the experiment only shows the feasibility of the damping.

\section{Numerical analysis and simulations}

The cable behavior obtained via a FEA including a proprietary routine for the SMA behavior agreed with the experimental results. Some degree of "viscosity" was introduced to the ELSA cable in agreement with the wax effects. The cubic model was primarily used to simulate the SMA. In fact, the elastic part of the classical bilinear model avoids damping effects at low amplitude (for strains under $1 \%$ ) with a residual harmonic oscillatory behavior [46], contrary to that observed in the IFSTTAR cable. Using the data available for cable 1, a FEA simulation can be attained with satisfactory results.

In the ELSA cable the SMA damper was installed vertically at $22 \%$ of the cable length, and the cable was composed of four steel cable strands ( $E=200 \mathrm{GPa}$ and $15 \mathrm{~mm}$ in diameter) inserted into a polyethylene sheath $(E=600 \mathrm{MPa}$ ) with a thickness of $3.5 \mathrm{~mm}$ and filled with wax $(E=27 \mathrm{MPa})$. The cable has a mass per unit length of approximately $m_{\mathrm{L}}=9.8 \mathrm{~kg} / \mathrm{m}$. The model was built using the finite element software ANSYS 13.0 with the Mechanical APDL interface. The cable was represented by 100 beam elements (BEAM3 element type) and both extremities were clamped (displacements and rotations were fixed to zero). The stiffness-inertia $\left(\mathrm{EI}=35,400 \mathrm{Nm}^{2}\right)$ and stiffness-area $\left(\mathrm{EA}=1.3 \times 10^{8} \mathrm{~N}\right)$ products of the entire cross section were calculated. For these analyzes, an 

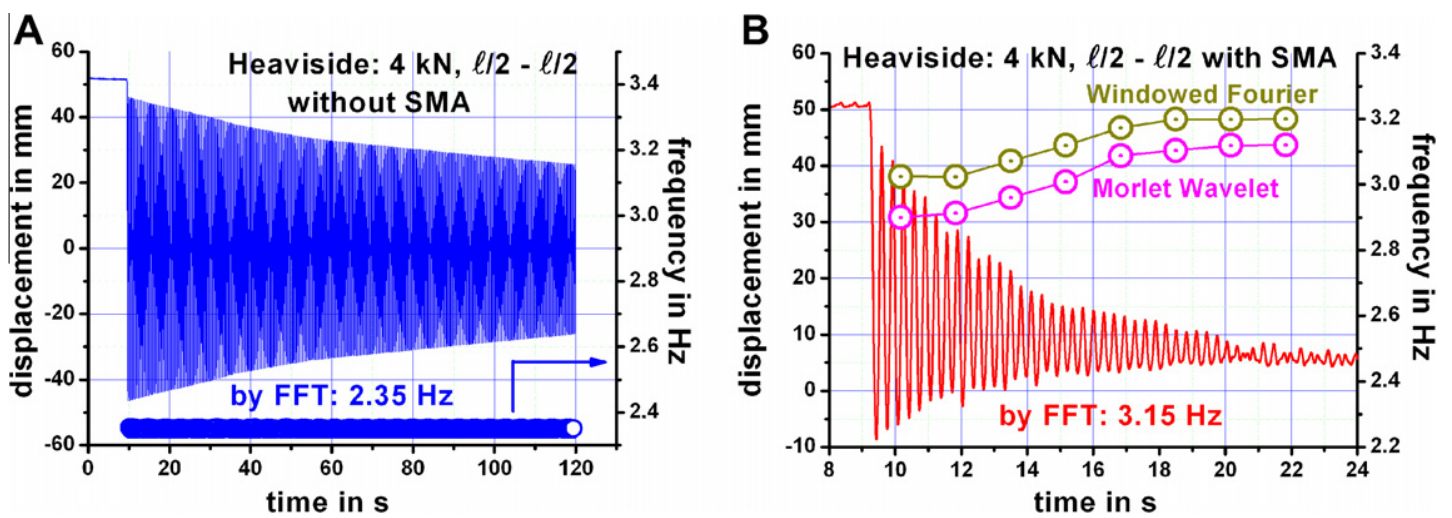

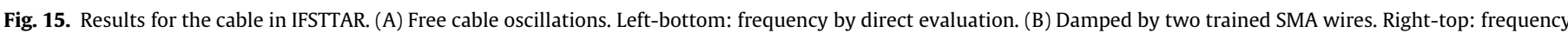
values by WFT and MWT.
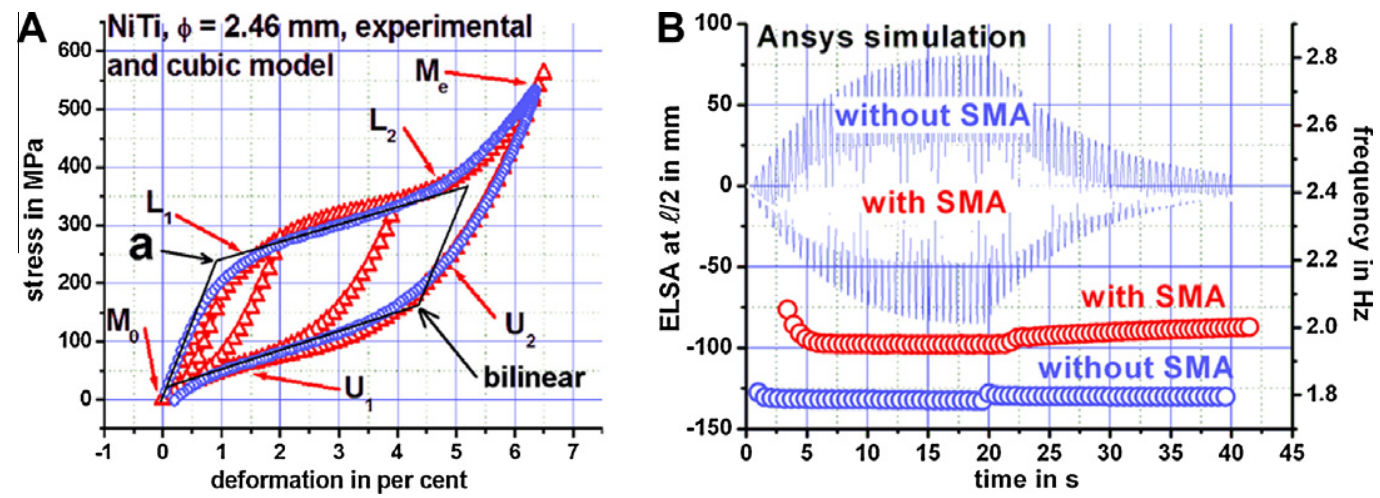

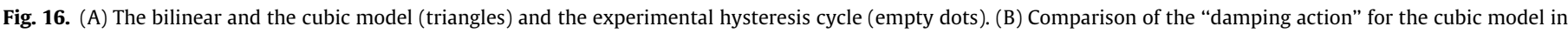
the ELSA cable in the middle of the cable. Included the frequency from local analysis for the calculated curves (without and with SMA).
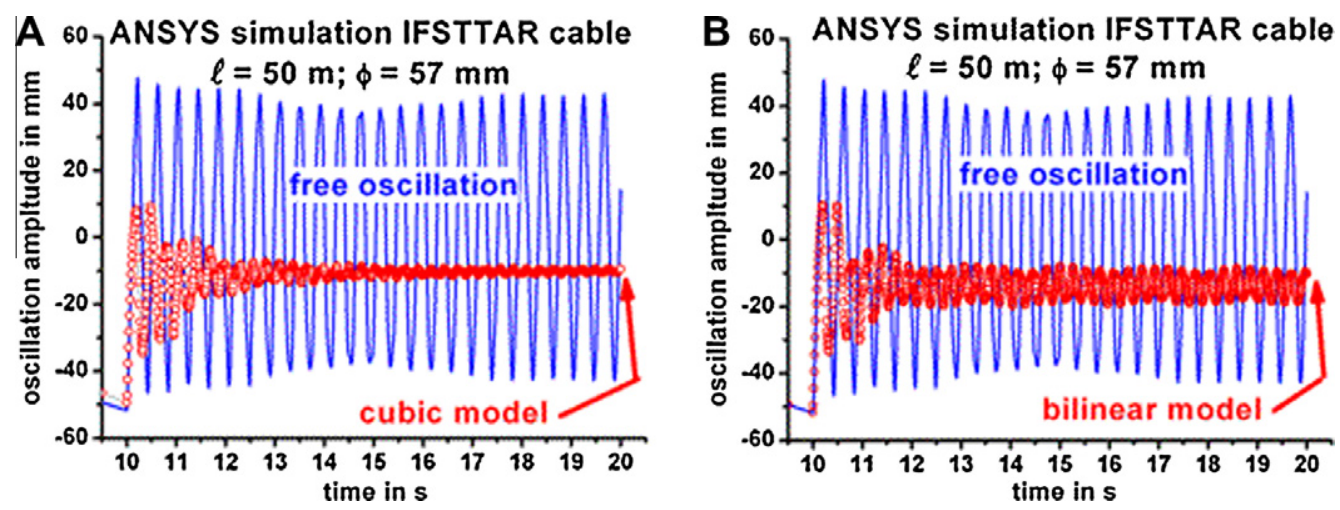

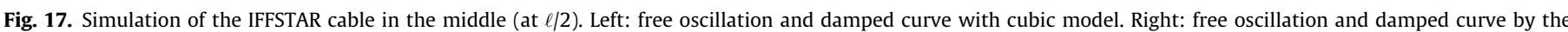
bilinear model.

equivalent density, $\rho^{*}$, Young's modulus, $E^{*}$ and inertia moment, $I^{*}$ were defined to simulate a uniform circular beam with the same properties of the cable made from different materials. Knowing that the cable length and area are $L=45 \mathrm{~m}$ and $A=0.0045 \mathrm{~m}^{2}$, respectively, and the following products represent the real cable $\left(m_{\mathrm{L}}=\rho^{*} \quad A=9.8 \mathrm{~kg} / \mathrm{m}, E^{*} I^{*}=35,400 \mathrm{Nm}^{2}, E^{*} A=1.3 \times 10^{8} \mathrm{~N}\right)$, then the equivalent properties of the cable are $\rho^{*}=2175 \mathrm{~kg} / \mathrm{m}^{3}$, $E^{*}=29 \mathrm{GPa}$ and $I^{*}=1.2 \times 10^{-6} \mathrm{~m}^{4}$.

The damper was modeled using a single bar element (LINK180 element type) attached to the cable at one end and pinned to the ground at the other end. The damper used was a single $4 \mathrm{~m}$ long NiTi wire with a diameter of $2.46 \mathrm{~mm}$. A classic bilinear and a cubic model was implemented in ANSYS via its USERMAT architecture and used to improve the description of the SMA behavior. This model was called "cubic" (Fig. 16A) because the loading and unloading paths of the cycle were represented by cubic polynomial equations instead of a series of straight lines used in the classical bilinear model, which yields incorrect results for strains under $1 \%$ [46]. The path from $(0,0)$ to the "a" point and backwards is elastic without conversion of mechanical energy into heat (see, for instance, the results presented in Fig. 17B).

Four different points on the loading and unloading paths of the experimental curve from a trained sample were used to build the model. Both paths were constructed using the same starting $\left(M_{\mathrm{o}}\right)$ 
Table 1

Data used to identify the cubic fit.

\begin{tabular}{lllllll}
\hline Point & $M_{0}$ & $M_{\mathrm{e}}$ & $L_{1}$ & $L_{2}$ & $U_{1}$ & $U_{2}$ \\
\hline$\varepsilon(\%)$ & 0 & 6.36 & 1.66 & 4.3 & 1.12 & 0.045 \\
$\sigma(\mathrm{MPa})$ & 0 & 531 & 252 & 350 & 52 & 200
\end{tabular}

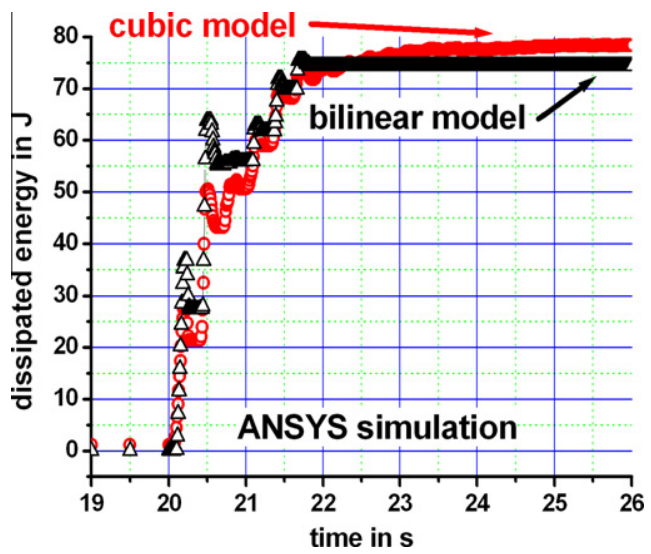

Fig. 18. Comparison of the accumulated energy between the bilinear (open triangles) and the cubic model for the IFSTTAR cable (open dots).

and ending $\left(M_{\mathrm{e}}\right)$ points. Two other points for the loading path $\left(L_{1}\right.$ and $\left.L_{2}\right)$ and unloading path $\left(U_{1}\right.$ and $\left.U_{2}\right)$ were selected from the experimental curve. The $\sigma, \varepsilon$ coordinates used are given in Table 1 .

The transformation and retransformation pathways of the hysteretic branch were considered cubic polynomials. The coefficients $c_{0}-c_{3}$ of the each cubic polynomial equation $\left(\sigma=c_{3} \varepsilon^{3}+c_{2} \varepsilon^{2}+\right.$ $c_{1} \varepsilon+c_{0}$ ) were determined by forcing the curve to pass through the four selected points. Adequately selecting these points can provide very good agreement with experimental data. Another polynomial equation was derived for partial cycles within the hysteresis by controlling the location and slope at the beginning and end of the partial cycle.

Fig. 16B shows the simulated FEA response (both with and without the SMA) when a sinusoidal signal is applied to the ELSA cable under the experimental conditions described in Section 3. The signal with the highest amplitude was associated to an undamped cable. The cable was excited using a sinusoidal force that varied between 0 and $100 \mathrm{~N}$ with a frequency of $1.81 \mathrm{~Hz}$ for the free cable and $2.04 \mathrm{~Hz}$ when a damper was used. After $20 \mathrm{~s}$ of excitation, the force is released and the cable oscillates freely for another $20 \mathrm{~s}$. The experimental and simulated results were in good agreement and showed the clear, relevant effects of the SMA damping of the stay cables.

\subsection{Simulation corresponding to the IFSTTAR cable}

This simulation is similar to the ELSA simulation but adapted to the IFSTTAR horizontal cable assuming an initial tension of $960 \mathrm{kN}$.
Fig. 17 compares the simulated results using the cubic model (A) to those of the classical bilinear model (B) and includes the free oscillations of the cable as a reference. In the bilinear model, the final oscillation amplitude remains constant. The cubic model simulates a certain degree of dissipation via the damper even for small amplitude cycles, according to the experimental data, which the bilinear model [46] cannot achieve. In the bilinear model, the oscillatory energy is dissipated in the very first cycle and later remains constant (Fig. 18). In the simulated "cubic" damper, the dissipated energy continues to increase until the oscillation amplitude of the cable practically vanishes (Fig. 17A) furnishing calculated results similar to experimental measurements. The results suggest that the bilinear model cannot visualize correctly the lower strains as, for instance, shows Fig. 17B and appears in Ref. [46].

\subsection{Frequency analysis}

Standard Fourier transformations typically use the fast Fourier transform (FFT). When necessary, the continuous Fourier transform is calculated using a "dense" representation of the frequencies. The clearly nonlinear and non-conservative action of the SMA damper produces a progressive evolution of the frequency in the transitory signals. In fact, the SMA induces the damping action by converting the mechanical oscillation into heat, which was clearly dependent on the oscillation amplitude. The frequency versus the time can be directly calculated from high-quality signals via the direct evaluation of frequencies from the time for one complete oscillation as shown by the bottom open dots in Fig. 14A.

Characterizing the frequency evolution with time was first accomplished using the WFT. A second approach uses a wavelet transform [47]. The MWT [48] has a sinusoidal shape multiplied by a Gaussian. The wavelet is of potential interest for detecting the reduced changes in frequency versus time (see the results in Fig. 15B). For the ELSA cable, the FFT indicated the primary frequencies were $1.8 \mathrm{~Hz}$ for the free cable and $2.05 \mathrm{~Hz}$ for the SMA damped cable. Direct measurement of the time interval of the damped curve (Fig. 14A) showed a change from 2.35 to 2.10 versus the measurement time with a minimum at $2.02 \mathrm{~Hz}$.

Table 2 includes the corresponding frequencies and amplitudes for the IFSTTAR cable both when left free and damped at different positions calculated using the FFT (Fig. 19). Using the actuator and damper situated at $\ell / 2$, the FFT only yields one frequency with a relevant amplitude reduction: from "free" to "SMA damped" changes from 27.9 to $3.2 \mathrm{~mm} \mathrm{~s}$. When the action is performed at other positions, other frequencies are also activated and reasonably damped by the SMA. See Table 2 and Fig. 19B with the frequencies for the Heaviside decay situated in $\ell / 8$ when the laser measures in $\ell / 16$. The small systematic differences between the MWT and WFT are associated with the rough scaling adjustments in the MWT.

Upon the return of the Heaviside signal, the WFT and MWT yield similar results (Fig. 15B) according to the directly evaluated oscillation time. The classical approach associate to frequency sampling commonly used to study larger data volumes and frequencies [49] cannot be used for the frequency evolution of cables. In our

Table 2

The fast Fourier transform (FFT) for IFSTTAR cable using the complete set of experimental data. The algorithm divides the amplitudes by the total time.

\begin{tabular}{|c|c|c|c|c|c|c|}
\hline \multirow[t]{2}{*}{ First three frequencies in $\mathrm{Hz}$ extracted from $\mathrm{FFT}$} & \multicolumn{3}{|c|}{ With SMA } & \multicolumn{3}{|c|}{ Without SMA } \\
\hline & $f_{1}$ & $f_{2}$ & $f_{3}$ & $f_{1}$ & $f_{2}$ & $f_{3}$ \\
\hline Heaviside step at $\ell / 2$; SMA at $\ell / 2$; FFT from sensor situated at $\ell / 2$ & 3.15 & 6.14 & 6.37 & 2.36 & 4.70 & 7.05 \\
\hline Amplitude (mm) & 3.20 & 0.27 & 0.30 & 27.89 & 0.11 & 0.88 \\
\hline Heaviside step at $\ell / 8$; SMA at $\ell / 16$;FFT from sensor situated at $\ell / 16$ & 2.46 & 4.85 & 7.17 & 2.36 & 4.73 & 7.1 \\
\hline Amplitude $(\mathrm{mm})$ & 0.46 & 0.21 & 0.02 & 1.88 & 1.87 & 0.78 \\
\hline
\end{tabular}




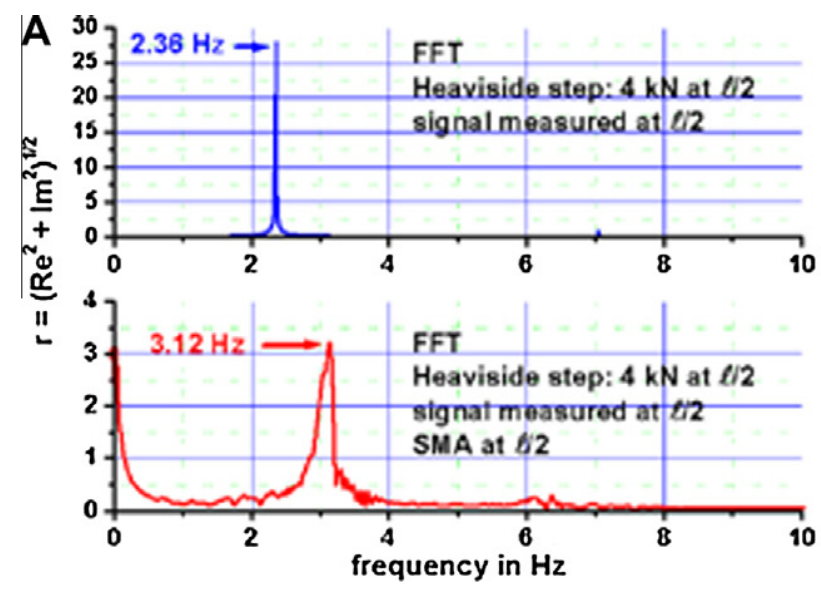

Fig. 19. FFT for the IFSTTAR cable. (A) Actuator, damper and sensor at $\ell / 2$. (B) Actuator and damper, respectively, at $\ell / 8$ and $\ell / 16$. Sensor at $\ell / 16$.

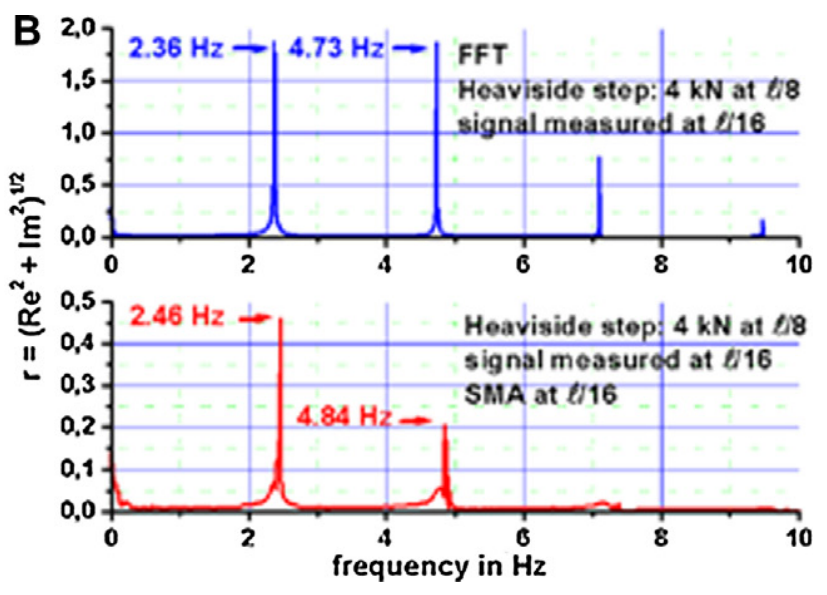

wires used). The observation of the S-shaped hysteresis cycles in the material shows that the equivalent stiffness in the force/displacement progressively reduces as the transformation advances. The $k_{\text {SMA }}$ values have been obtained using cycle 20 in a sample with $\ell=103.8 \mathrm{~mm}$ and extrapolated to the damper length used two parallel wires of $\ell^{*}=1260 \mathrm{~mm}$.

The relative frequency change in the cable with SMA $\left(f_{G L O B A L}\right)$ and alone $\left(f_{G L O B A L}-f_{\text {SMA }}\right)$ can be written as the following:

$\frac{f_{G L O B A L}-f_{\mathrm{SMA}}}{f_{G L O B A L}}=\frac{\frac{1}{2 \pi} \sqrt{\frac{k_{G L O B A L}}{m}}-\frac{1}{2 \pi} \sqrt{\frac{k_{\mathrm{SMA}}}{m}}}{\frac{1}{2 \pi} \sqrt{\frac{k_{G L O B A L}}{m}}}=1-\sqrt{\frac{k_{\mathrm{SMA}}}{k_{G L O B A L}}}$

To evaluate the $k_{\text {cable }}$ value, it is thought that only half of the cable length affects the dynamic actions. The calculated value of $88.6 \mathrm{kN} / \mathrm{m}$ yields an $f_{\text {GLOBAL }}$ of $3.20 \mathrm{~Hz}$, which indicates a reduced amplitude. For the larger amplitudes in Table 3 , the $f_{\text {GLOBAL }}$ approaches $2.9 \mathrm{~Hz}$. The calculated MWT (with windows of 540 points or $1.8 \mathrm{~s}$ ) or WFT values shown in Fig. 15B yield similar results.

This rough model is able to provide an initial indication of the frequency changes caused by the SMA damper. The primary frequency change relates to the difference between the presence or absence of the SMA. This change is approximately $1 \mathrm{~Hz}$ in the IFSTTAR measurements. In fact, the primary changes relate to prestressing. Moreover, the use of more appropriate length of SMA wires reduces the working stress associated to the experimental deformations. The amplitude evolution with the damping action remained under $0.5 \mathrm{~Hz}$. The action of pre-stressing was partially complementary and opposite. Increasing the frequency increases the damping actions and reduces the life of the damper.

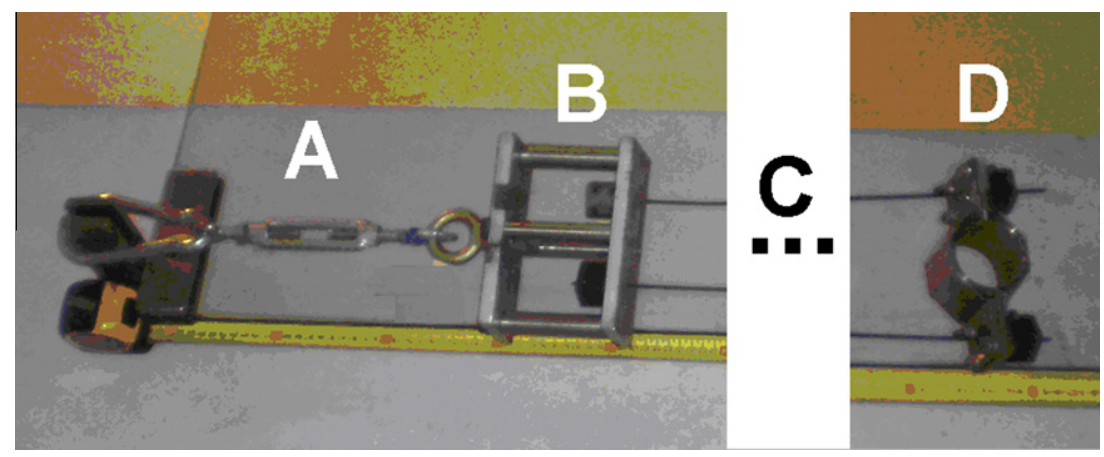

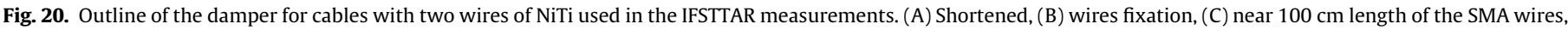
(D) fixation for the IFSTTAR cable. 

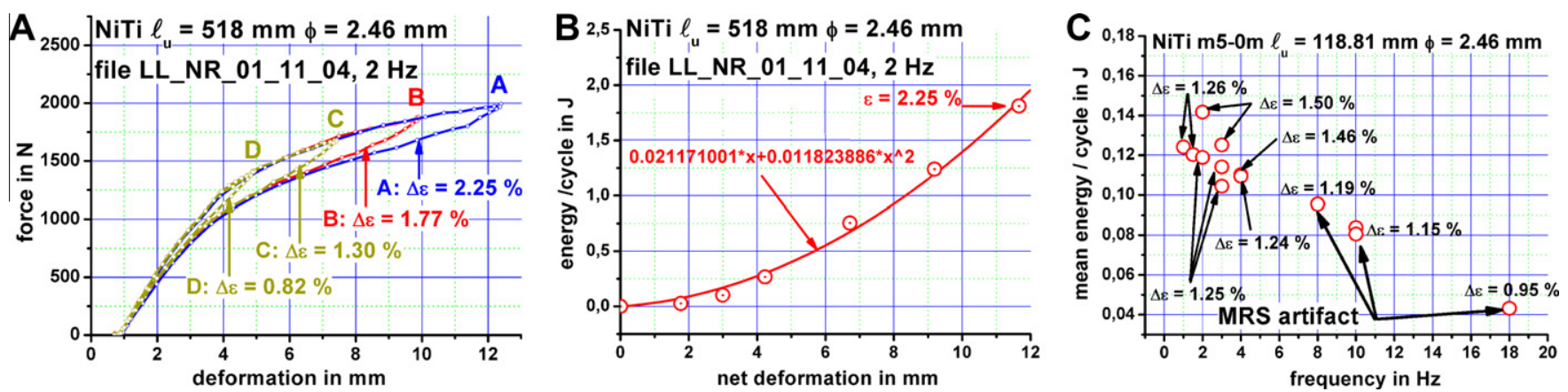

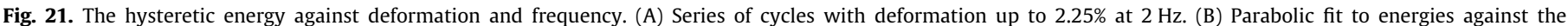
deformation. (C) Effect of frequency on cycling. At constant deformation the points fit to one straight line.

The frequency analysis using FFT for the ELSA cables yielded values of 1.8 and $2.03 \mathrm{~Hz}$. The signals with enough signal-to-noise ratios permit the direct determination of each complete oscillation of the ELSA cable (Fig. 13A). The frequency changes in the simulation were similar to the values observed in the experimental data. The largest change in the frequency is between the free oscillation and damped cable $(0.25 \mathrm{~Hz}$ in ELSA and $0.8 \mathrm{~Hz}$ in the IFSTTAR cable). Minor changes occur with the evolution of the amplitude via the action of the SMA damper: approximately $0.1 \mathrm{~Hz}$ as shown by the experiments (Fig. 13) and $0.1 \mathrm{~Hz}$ by the simulation (for the ELSA cable) and 0.2 or $0.3 \mathrm{~Hz}$, respectively, for the IFSTTAR cable shown in Fig. 15B.

\section{Application remarks}

Global analysis provides some ideas for the application of SMA dampers (NiTi wires with $2.46 \mathrm{~mm}$ diameters). Two actions are required for the experimental analysis. The first focuses on the length of the SMA wires. In particular, it is expected that the dampers reduce the oscillation amplitude by one half. Considering that $\mathrm{x}$ is the residual amplitude after damping, the required length $\ell$ of the SMA wires was as follows:

$0.010 \ell=x(\mathrm{NiTi})$

Eq. (7) establishes the appropriate SMA length to ensure an extended fracture life: the SMA strains remain under $1 \%$. For instance, at this length, the fracture life is over 4.5 million working cycles for strains under $1.0 \%$. The SMA studies clearly indicate the alloys behave nonlinearly. The use of several SMA wires is possible; however, when the thermal coupling between them is avoided. For instance, a squirrel cage could be built with the wires.

SMA dampers are built using one or more wires with the same diameter. The measurements made here indicate that the force generated by the SMA is a small percentage of the total forces exerted on the cable. From a practical point of view, the primary oscillation frequency of the cables studied was similar. In fact, both the ELSA and IFSTTAR cables, as well as the thinner wire studied in the Dept. of Structural Mechanics in Pavia (Italy), produced similar frequencies of approximately 2-7 Hz. Roughly analogous oscillation amplitudes were studied during these observations (between $5 \mathrm{~mm}$ and $6 \mathrm{~cm}$ ). Under these conditions, the inertial force of the cable, which should be damped, was proportional to the cable's mass. The mass ratio between Nantes and ELSA versus Pavia was close to 1000 . The experiments obtained appropriate results uses a single SMA wire with a diameter of $2.46 \mathrm{~mm}$ at ELSA (the mean SMA force is close to $1.5 \mathrm{kN})$, two wires ( $3 \mathrm{kN}$ ) at IFSTAR and one wire with a diameter of $0.1 \mathrm{~mm}$ (mean force close to $2 \mathrm{~N}$ ) in Pavia.
The experimental analysis indicated an initial approach for preparing an SMA damper for another cable with $N$ wires and a $2.46 \mathrm{~mm}$ diameter requires the following:

(a) Evaluate the mass of the oscillating cable.

(b) Establish the mass ratio relative to the steel mass in the ELSA cable. This ratio establishes the force ratio for the SMA wire relative to the ELSA damper wire.

This initial approach establishes that the force in the SMA is "proportional" to the number of SMA wires $\left(N_{\text {wire }}\right)$ times their cross section, $N_{\text {wire }} \pi r^{2}$. The general ratios using the same diameter of the SMA wires read as follows:

$$
\begin{aligned}
\text { Mass ratio } & =\frac{m_{\text {new cable }}}{m_{E L S A \text { cable }}}=\text { force ratio }_{\mathrm{SMA}} \\
& =\frac{\text { force }_{\mathrm{SMA}} \text { in the new cable }}{\text { force }_{\mathrm{SMA}} \text { in the ELSA cable }} \\
& =\frac{\left(\left(N_{\text {wires }}\right) * \pi * r^{2}\right)_{\text {SMA in the new cable }}}{\left(\pi * r^{2}\right)_{\text {SMA in ELS cable }}}=N_{\text {wires }}
\end{aligned}
$$

The $N$ value roughly approximates the number of required wires without thermal coupling. In general, a squirrel cage distribution seems reasonable. Fig. 20 shows the available distance is even higher, i.e., approximately $100 \mathrm{~mm}$ between the SMA wires.

As the hysteretic behavior was affected by the external temperature based on the Clausius-Clapeyron equation, the maximum and minimum external temperatures were very relevant to the behavior of the SMA in the open air space as describes the part 2.3.2. Materials with flat (rectangular) cycles were not deemed appropriate without a more detailed analysis. An outline of the damper is shown in Fig. 20. Its structure focused on two SMA wires (with different diameters) and the SMA length. The shortened device (A) was used to induce a minor initial stress in the SMA wires. A trained wire was used both with and without pre-stressing for the tests performed on cable number 1 at ELSA. Some analyzes associated with pre-stressing effects were conducted during the IFSTTAR measurements. The wire-induced forces on the cable were between zero and $1500 \mathrm{~N}$ according to the imposed strain. Forces approaching or under $1 \mathrm{kN}$ had higher fracture lives. Clamps can be fixated to the bottom surface and the cable. Each wire can independently avoid compression, sliding in fixations B and D as shown in Fig. 20. Mounting the SMA dampers requires preparing the appropriate number of wires required for the force of the damper with a length that ensures the appropriate fracture-life (maximum strain of approximately $1 \%$ ). In our case, the maximum strain-induced forces for one wire not overcomes $1.5 \mathrm{kN} /$ wire for each NiTi wire of $2.46 \mathrm{~mm}$ of diameter. 
For the practical numerical analysis, the particular frequencies affecting the damper (and their amplitudes) require adapted measurements for the cable frequencies, which permit a satisfactory evaluation of the dissipated energies versus the amplitude and frequency. Using cycles at $0.01 \mathrm{~Hz}$ only induce a rough result. Fig. 21 shows series of experimental measurements against the strain and the frequency. The measurements permits an appropriate representation using a parabolic fit for strains under $2.5 \%$. Moreover, one straight line was useful for the decrease of the hysteretic energy against the frequency between 1 and $18 \mathrm{~Hz}$.

\section{Conclusions}

An in-depth study of the SMA properties is relevant for damping applications. In particular, the study of changes associated with creep effects and with the fracture level. NiTi dampers might reduce the oscillation amplitude to one-half or less for damped stay cables. Their fracture life (at strain levels near $1 \%$ ) is satisfactory for several days of continuous cycling of the cables studied.

The study of the damper behavior at temperatures between $50{ }^{\circ} \mathrm{C}$ and $-20^{\circ} \mathrm{C}$ using SMA trained wires with S-shaped hysteretic behavior was clearly advantageous for their application in bridges that work continuously in both summer and winter.

Accurate numeric analysis requires measurements at reduced strain (i.e., up to $2.5 \%$ ) and the basic frequency of the cable. Moreover, dependence on the frequency is convenient. Measurements realized at constant strain, at several frequencies, permits to determine quantitatively the dependence of energies against strain and frequency.

FEA simulations require a good phenomenological model. The "cubic" model provides improved results at lower strains (i.e., $0.7-1.5 \%$ ). These simulations are coherent with the experimental results for the studied SMA damped cables in ELSA and IFSTTAR facilities.

The pre-stressing of the SMA induces changes in the first harmonic of approximately $1 \mathrm{~Hz}$. The reduction of the oscillation amplitude by the SMA induces less than $0.5 \mathrm{~Hz}$. A study of the local frequency evolution versus time has been conducted by directly evaluating the signals using windowed Fourier transform and by Morlet wavelet transform. The results are similar; however, the direct evaluation of these signals versus time, while very interesting, is quite sensitive to the signal-to-noise ratio.

The main frequency change between the free and SMA damped cables is associated with the pre-stressing of the SMA. The global frequency of the device (cable and SMA) was associated to the additional stiffness of the cable and SMA $\left(\mathrm{k}_{G L O B A L}=k_{\text {cable }}+k_{\mathrm{SMA}}\right)$. Subsequent frequency reductions versus time were associated with the minor changes induced by the evolution of the oscillation amplitude. The SMA cycles with the associated displacement of the working point induce a time evolution of the $k_{\mathrm{SMA}}$. The minor frequency increase at reduced oscillation amplitudes relates the progressive change of the SMA stiffness with the progressive strain reduction.

\section{Acknowledgements}

The authors gratefully acknowledge the decisive support from G. Magonette, D. Tirelli and, in particular from B. Zapico in ELSA Lab. (EU-Italy) and by L. Dieng, D. Bruhat and R. Michel in IFSTTAR (France). The support from SANEF (France) permitting the visit to Echinghen Viaduc is acknowledged. The preliminary study realized for thinner cables in the Pavia group (Prof. F. Casciati and coworkers) that permits a roughly test of formula 8 was gratefully acknowledged. The research work of this paper was realized in the frame of the SMARTeR project ESF 2007-09 supported by MICINN BIA2006-27041-E and, actually, by MICINN - MAT200908654 .

\section{References}

[1] <http://www.esf.org/activities/eurocores/completed-programmes/s3t.html>.

[2] <http://www.esf.org/activities/eurocores/completed-programmes/s3t/ projects.html $>$.

[3] <http://www.esf.org/index.php?eID=tx_nawsecuredl\&u=0\&file=fileadmin/be user/activities/EUROCORES/SMARTeR.pdf \&t=1337851967\&hash=ff572cf0012 1d04d2849f6c09a45968cbb75f795>.

[4] <http://www.lcpc.fr/english/news-events/news/article/launching-of-theeuropean-project>.

[5] School and Symposium on Smart Structural Systems Technologies, 6-9 April, 2010, a FEUP, Porto, Portugal (S3T-ESF Meeting). Published in S(3)T 2010, Barros R, Preumont A, editors. Faculdade de Engenharia da Universidade do Porto; 2010, ISBN: 978-989-96697-0-3.

[6] Janocha H, editor. Adaptronics and smart structures. Berlin: Springer; 1999.

[7] Lord Corporation. <http://www.lord.com>.

[8] <http://en.wikipedia.org/wiki/Dongting_Lake_Bridge>.

[9] Chen ZQ Wang XY, Ko JM, Ni YQ Spencer BF Jr., Yang G. MR damping system on Dongting Lake cable-stayed bridge. Smart Structures and Materials 2003: Smart Systems and Nondestructive Evaluation for Civil Infrastructures. Liu Shih-Chi, editor. Proceedings of the SPIE, vol. 5057; 2003. p. 229-35. doi:http:// dx.doi.org/10.1117/12.498072.

[10] Otsuka K, Wayman CM, editors. Shape memory materials. Cambridge: Cambridge University Press; 1998.

[11] Lovey FC, Torra V. Shape memory in Cu-based alloys: phenomenological behavior at the mesoscale level and interaction of martensitic transformation with structural defects in Cu-Zn-Al. Prog Mater Sci 1999;44:189-289.

12] Janke L, Czaderski C, Motavalli M, Ruth J. Application of SMA in civil engineering structures - overview, limits and new ideas. Mater Struct 2005;38:578-92.

[13] Wilson JC, Eeri M, Wesolowsky MJ. SMA for seismic response modification: a state of the art review. Earthquake Spectra 2005;21:569-601.

[14] Song G, Ma N, Li HN. Applications of shape memory alloys in civil structures. Eng Struct 2006;28:1266-74.

[15] DesRoches R, Delemont M. Seismic retrofit of simply supported bridges using shape memory alloys. Eng Struct 2002;24:325-32.

[16] Wilde K, Gardoni P, Fujino Y. Base isolation system with shape memory alloy device for elevated highway bridges. Eng Struct 2000;22:222-9.

[17] Torra V, Isalgue V, Martorell F, Lovey FC, Sade M, Molina FJ. From physical time dependent properties to guaranteed shape memory alloys dampers. In: Proc of 13th world conf on earthquake engineering; 2004. Paper No. 1332.

[18] Torra V, Isalgue A, Martorell F, Terriault P, Lovey FC. From experimental data to quake damping by SMA: a critical experimental analysis and simulation. In: Proc of 9th world seminar on seismic isolation, energy dissipation and active vibration control of structures, vol. 2; 2005. p. 241-8.

[19] Isalgue A, Lovey FC, Terriault P, Martorell F, Torra RM, Torra V. SMA for dampers in civil engineering. Mater Trans 2006;47:682-90.

[20] Torra V, Isalgue A, Martorell F, Terriault P, Lovey FC. Buit in dampers for family homes via SMA: an ANSYS computation scheme based on mesoscopic and microscopic experimental analyses. Eng Struct 2007;29:1889-902.

[21] Walter Yang CS, DesRoches R, Leon RT. Design and analysis of braced frames with shape memory alloy and energy-absorbing hybrid devices. Eng Struct 2010;32:498-507.

[22] Ozbulut OE, Hurlebaus S. Evaluation of the performance of a sliding-type base isolation system with a NiTi shape memory alloy device considering temperature effects. Eng Struct 2010;32:238-49.

[23] Sharabash AM, Andrawes BO. Application of shape memory alloy dampers in the seismic control of cable-stayed bridges. Eng Struct 2009;31:607-16.

[24] Andrawes B, DesRoches R. Effect of ambient temperature on the hinge opening in bridges with shape memory alloy seismic restrainers. Eng Struct 2007;29: 2294-301.

[25] (a) See, in reference [5] the papers: (a) Experimental study of damping in civil engineering structures using smart materials ( $\mathrm{Cu}-\mathrm{Al}-\mathrm{Be}$ - NiTi SMA). Applications to steel portico and to stayed cables for bridges (The SMARTeR project), Torra V, Lovey FC, Terriault P, p. 369-99.(b) SMA Smart Materials (CuAlBe and NiTi) for use in damping: the implications of reliability for long time applications and aging behaviour, Isalgue $A$, Torra V, Carreras $G$, Auguet $C$, Lovey FC, p. 471-481.(c) Self-heating effects on the hysteresis width of SMA Auguet C, Carreras G, Isalgue A, Torra V, p. 483-95.

[26] Castellanos MG. Application of seismic devices to Italian cultural heritage structures. In: 7th Int seminar on seismic isolation, passive energy dissipation and active control of vibrations of structures Assisi, Italy, October 2-5, 2001.

[27] Information from the SMA devices for seismic protection of cultural heritage structures can be extracted from Proceedings of the Final Workshop of ISTECH Project: Shape Memory Alloy Devices for Seismic Protection of Cultural Heritage Structures, 23 June, Joint Research Centre, Ispra, Italy, 2000. <http:// www.archquake.com/pdf-pubblicazioni/ Assisi2001.Cultural\%20Heritage.pap.pdf $>$.

[28] ANSYS. <http://www.ansys.com/>. 
[29] Sade M, Yawny A, Lovey FC, Torra V. Pseudoelaticity of Cu-Al-Be single crystals: unexpected mechanical behavior. Mat Sci Eng A - Struct, Reference: MSEA-D-11-00248R1, <http://dx.doi.org/10.1016/j.msea.2011.07.021>.

[30] Torra V, Isalgue A, Auguet C, Carreras G, Lovey FC, Terriault P. Damping in Civil Engineering using SMA. Part II. Particular properties of NiTi for damping of stayed cables in bridges. Can. Metall. Quart, http://dx.doi.org/10.1179/ 1879139512 Y.0000000036.

[31] Torra V, Isalgue A, Soul H, Lovey FC, Yawny A. Pseudoelastic fatigue of NiTi wires. Frequency and size effects on damping capacity. Smart Mater Struct 2010;19(8):085006. http://dx.doi.org/10.1088/0964-1726/19/8/08500 [7pp].

[32] Baril Y, Brailovski V, Terriault P. Fatigue properties of superelastic Ti-N filaments used in braided cables for bone fixation. Adv Sci Technol 2008;57:235-40.

[33] Tobushi H, Hachisuka T, Yamada S, Lin PH. Rotating-bending fatigue of a NiTi shape memory alloy wire. Mech Mater 1997;26:35-42.

[34] Azevedo MG, Fonseca R, Lopes VT. The influence of high amplitude cycling straining on the behaviour of superelastic NiTi. Int J Fatigue 2006;28: 1087-91.

[35] Maletta C, Furgiuele F. Analytical modeling of stress-induced martensitic transformation in the crack tip region of nickel-titanium alloys. Acta Mater 2010;58:92-101.

[36] Plotino G, Grande NM. A review of cyclic fatigue testing of nickel-titanium rotary instruments. J Endodont 2009;35:1469-76.

[37] McNichols JL, Brooks PC. NiTi fatigue behaviour. J Appl Phys 1981;52(12): 7442-4.

[38] Pelton AR. Nitinol Fatigue: A Review of Microstructures and Mechanisms. ] Mater Eng Perform, (JMEP) doi:http://dx.doi.org/10.1007/s11665-011-9864-9.

[39] Lagoudas DC, Miller DA, Rong L, Kumar PK. Thermomechanical fatigue of shape memory alloys. Smart Mater Struct 2009;18(8):085021. http://dx.doi.org 10.1088/0964-1726/18/8/08502 [12pp].
[40] Casciati F, Casciati S, Faravelli L, Marzi A. Fatigue damage accumulation in a Cu-based shape memory alloy: preliminary investigation. Comput Mater Continua 2011;23(3):287-306.

[41] Torra V, Isalgue A, Martorell F, Lovey FC, Terriault P. Damping in civil engineering using SMA. Part I: Particular properties of CuAlBe for damping of family houses. Can Metall Quart 2010;49(2):179-90.

[42] Carreras G, Isalgue A, Torra V, Lovey FC, Soul H. Metastable effects on martensitic transformation in SMA - Part V. Fatigue-life and detailed hysteresis behavior in NiTi and Cu-based alloys. J Therm Anal Calorim 2008;91(2):575-9.

[43] Aernoudt E, Van Humbeeck J, Delaey L, Van Moorleghem M. Copper-base shape memory alloys: alloys for tomorrow. In: Torra V, editor. Proceedings of the comett course: the science and technology of shape memory alloys. Univ. Illes Balears; 1989. p. 221.

[44] Wollants P, Roos JR, Delaey L. Thermally-induced and stress-induced thermoelastic martensitic transformations in the reference frame of equilibrium thermodynamics. Prog Mater Sci 1993;37(3):227-88.

[45] Isalgue A, Torra V, Yawny A, Lovey FC. Metastable effects on martensitic transformation in SMA Part VI. The Clausius-Clapeyron relationship. J Therm Anal Calorim 2008;91(3):991-8.

[46] Ben Mekki O, Auricchio F. Performance evaluation of shape-memory-alloy superelastic behavior to control a stay cable in cable-stayed bridges. Int J NonLinear Mech 2010. doi: http://dx.doi.org/10.1016/i.ijnonlinmec.2010.12.002.

[47] Casciati F, Faravelli L, Fuggini C. Cable vibration mitigation by added SMA wires. Acta Mech 2008;195:141-55. http://dx.doi.org/10.1007/s00707-0070541-X.

[48] <http://en.wikipedia.org/wiki/Morlet_wavelet>, July 2011.

[49] Torrence C, Compo GP. A practical guide to wavelet analysis a practical guide to wavelet analysis. Bull Amer Met Soc 1998;79(1):61-78 [software and example is available at URL: <http://paos.colorado.edu/research/wavelets/>]. 